\title{
Article \\ EMC Component Modeling and System-Level Simulations of Power Converters: AC Motor Drives
}

\author{
Bernhard Wunsch ${ }^{1, * \mathbb{D}}$, Stanislav Skibin ${ }^{1}$, Ville Forsström ${ }^{2}$ and Ivica Stevanovic ${ }^{3}$ (D) \\ 1 ABB Research Switzerland, 5405 Baden, Switzerland; stanislav.skibin@ch.abb.com \\ 2 ABB Oy Drives, 00381 Helsinki, Finland; ville.forsstrom@fi.abb.com \\ 3 Federal Office of Communications OFCOM, 2501 Biel/Bienne, Switzerland; \\ ivica.stevanovic@bakom.admin.ch \\ * Correspondence: bernhard.wunsch@ch.abb.com
}

Citation: Wunsch, B.; Skibin, S.;

Forsström, V.; Stevanovic, I. EMC

Component Modeling and

System-Level Simulations of Power

Converters: AC Motor Drives.

Energies 2021, 14, 1568. https://

doi.org/10.3390/en14061568

Academic Editor: Anna Richelli

Received: 12 February 2021

Accepted: 9 March 2021

Published: 12 March 2021

Publisher's Note: MDPI stays neutral with regard to jurisdictional claims in published maps and institutional affiliations.

Copyright: (c) 2021 by the authors. Licensee MDPI, Basel, Switzerland. This article is an open access article distributed under the terms and conditions of the Creative Commons Attribution (CC BY) license (https:/ / creativecommons.org/licenses/by/ $4.0 /)$.

\begin{abstract}
EMC simulations are an indispensable tool to analyze EMC noise propagation in power converters and to assess the best filtering options. In this paper, we first show how to set up EMC simulations of power converters and then we demonstrate their use on the example of an industrial AC motor drive. Broadband models of key power converter components are reviewed and combined into a circuit model of the complete power converter setup enabling detailed EMC analysis. The approach is demonstrated by analyzing the conducted noise emissions of a $75 \mathrm{~kW}$ power converter driving a $45 \mathrm{~kW}$ motor. Based on the simulations, the critical impedances, the dominant noise propagation, and the most efficient filter component and location within the system are identified. For the analyzed system, maxima of EMC noise are caused by resonances of the long motor cable and can be accurately predicted as functions of type, length, and layout of the motor cable. The common-mode noise at the LISN is shown to have a dominant contribution caused by magnetic coupling between the noisy motor side and the AC input side of the drive. All the predictions are validated by measurements and highlight the benefit of simulation-based EMC analysis and filter design.
\end{abstract}

Keywords: electromagnetic compatibility (EMC); electromagnetic interference (EMI) filter; SPICE simulations; AC drives; conducted noise emissions; EMC filter; transmission line; power cable; chokes

\section{Introduction}

Switched-mode power converters transform the electrical power supplied to their inputs according to the requirements of the load connected at their output. While these converters provide high efficiency and control, their internal switching events also introduce high-frequency noise that pollutes the environment with conducted and radiated noise emissions [1,2]. In order to avoid any harm of such noise emissions to the device itself or to other equipment in the same environment, electromagnetic compatibility (EMC) norms limit the maximum allowed noise emissions of power converters and the minimum necessary immunity against external EM disturbances. In this work, we consider EMC norms on conducted noise emissions in the frequency band " $\mathrm{B}$ " ranging from $150 \mathrm{kHz}$ to $30 \mathrm{MHz}$ [3-5].

The objective of the EMC analysis of a converter is to design EMC filters that ensure compliance with these norms and to optimize these filters by minimizing cost and/or volume [6]. A powerful approach to EMC analysis is the usage of EMC simulations, where the entire power converter system including the external impedances is described in a form of an electrical circuit that captures the high-frequency noise sources as well as the noise propagation $[7,8]$. In principle, such simulations allow a detailed study of the system's electromagnetic behavior, including the spectrum and location of noise sources depending on the converter topology, the applied control scheme, and the semiconductor technology $[9,10]$, or of the noise propagation depending on the internal power components 
or the externally connected load and grid impedances [11]. Simulations can also help in the assessment and optimization of interconnects or the locations of grounding connections [12]. Importantly, such simulations can be done at an early design stage, before the converter is built, which enables short development time and minimizes risks of late redesigns. With all these benefits, a simulation-based EMC design seems to clearly outperform a conventional measurement-based approach [13].

However, all these benefits crucially depend on the quality of the simulation model. All the relevant components need to be identified and represented by corresponding circuit models valid in the frequency range of interest, where at high frequencies, the components behavior is far from ideal. Grounding connections and interconnects are no longer ideal shorts but introduce important coupling mechanisms [12]. Even the discrete components can couple to each other [1]. Ultimately, when the entire system is mapped to an accurate circuit model, the used circuit solver has to run numerically stable simulations within a reasonable time [13]. The active components such as semiconductor switches or the modeled nonlinear magnetic effects might require time-domain simulations spanning over a full fundamental period ( $20 \mathrm{~ms}$ for $50 \mathrm{~Hz}$ grid frequency), with a necessary resolution to resolve noise up to $30 \mathrm{MHz}$. These challenges explain why EMC analysis is still an art, despite all the advances in EMC technologies and in commercial software tools.

In this paper, we introduce and demonstrate a methodology to create, set up, and run an EMC simulation of power electronic converters. A state-of-the-art review of all EMC-critical components is given and a set of carefully developed component models is chosen [14-20] to build up an entire system-level model of industrial power converters. The used models not only accurately represent the EMC behavior of the power converter components, but also ensure stable and time-efficient simulations of the entire circuit. Prior work on EMC analysis of AC-drives has been reported in [21-27] and EMC analysis of DC-fed motors can be found in $[9,10,13,28-30]$. However, many of these publications are dealing with academic or low-power applications.

In this paper, the adopted methodology is applied to EMC analysis of conducted noise emissions in an industrial $75 \mathrm{~kW}$ AC motor drive (a variable-speed drive that controls the speed and torque of an induction motor connected at its output via a long, shielded motor cable). The system is represented by broadband stable circuits and is analyzed to identify the main noise propagation paths and the best noise filtering options. All effects predicted and explained by simulations are validated by measurements.

\section{State-of-the-Art Review of EMC Modeling of Power Electronic Components}

Efficient and accurate circuit models of power electronic components are necessary for EMC simulations of power electronic systems. In this section, we review the state-of-the-art in high-frequency modeling of all EMC-relevant power electronic components, such as chokes with non-linear magnetic cores, long cables, and motors, including resistors and capacitors, printed circuit boards (PCB) and housing, semiconductors, and line impedance stabilized networks (LISN).

Component modeling can be generally classified into two broad categories: physical or behavioral modeling [14,31]. Physical modeling is based on fundamental laws of physics, such as Maxwell equations. It requires the knowledge of geometry and electromagnetic characteristics of the modeled component and it can make use of analytical or numerical techniques to solve the equations and create an equivalent circuit model. The behavioral modeling, on the other hand, does not need this information and uses measured impedances of a component in various connection schemes to create an equivalent circuit that will reproduce that same behavior. In this paper, we follow this classification and designate the equivalent circuit models obtained using these two modeling procedures as physical and behavioral models, respectively. 


\subsection{Choke Modeling}

Electromagnetic interference (EMI) filters in power electronic systems are based on passive elements with inductors (chokes) used to reduce both common-mode (CM) and differential-mode (DM) EMI levels. The frequency characteristics of chokes may be much different from ideal when operating at high frequencies, due to parasitic capacitance of windings, leakage inductance, and frequency-dependent permeability of the magnetic cores, among other high-frequency effects. Accurate high-frequency models of single- and three-phase chokes are, therefore, an important building block in EMC simulations used for the filter design of power systems.

\subsubsection{Physical Models}

Physical models are based on analytical or numerical approaches, or a combination of the two, where electromagnetic equations are constructed and solved using the geometry and electromagnetic characteristics of the choke's windings and the core, which are either available from datasheets or need to be separately measured.

Analytical equations exist to estimate the magnetic fields inside the magnetic core and in the air, as well as the electric fields between two turns and between turns and core. These calculations can then be used to create an equivalent circuit of the choke [32-35], including leakage inductances [36-39] and parasitic (turn-to-turn and turn-to-core) capacitances [40-46]. These models can be effectively used for the purpose of optimizing the common-mode choke geometry and core materials [47,48].

Numerical approaches use various numerical techniques to solve Maxwell's equations for the entire choke or for some of its parts. Such techniques include the Finite-Element Method (FEM) [49-51] or 3-D Partial Element Equivalent Circuit (PEEC) method combined with the boundary integral method (BIM) [52,53]. Numerical models are more suitable for choke designs and their frequency-domain analysis.

\subsubsection{Behavioral Models}

Behavioral choke models can be further broadly grouped into two subcategories $[31,54]$. The first subcategory is behavioral models with circuit topologies that reflect the physical effects inside the choke (e.g., magnetic characteristics of the core). The second subcategory is black-box behavioral models having circuit topologies without any relation to the choke's internal physical effects, but correctly reproducing the measured behavior at its terminals.

Behavioral modeling based on black-box measurements can be carried out on a choke in different connection schemes using a spectrum analyzer [55-58], impedance analyzer [14,59], or vector network analyzer (VNA) [60-62]. The parameters of the corresponding equivalent circuits (with either fixed or variable topologies) are then extracted from measurements by (iterative) analytical formulas [14] and/or optimization algorithms for fitting the measured data, such as rational function approximations [31,63], vector fitting $[62,64,65]$, and evolutionary algorithms [14].

In behavioral models with circuit topologies reflecting the physical behavior of the core, the frequency-dependent core permeability (caused by eddy currents inside the core) is usually modeled using Cauer of Foster ladder networks, whose parameters are fitted to the measured complex permeability using different methods [54,66-73].

Recently, the Cauer RL ladder network from [66] has been extended by replacing linear inductors with Preisach [74] inductors. This model accurately captures high-frequency effects, saturation, and hysteresis in single- and three-phase chokes [15]. A description of the measurement setup used to characterize the magnetic properties and the parameter extraction procedure for the equivalent circuit has been provided. This model has been further extended in [16] to also account for dimensional resonance in ferrites. We use this methodology to create equivalent circuit models of the chokes for system-level simulations presented in this paper. 


\subsection{Multiconductor Cable Modeling}

Power cables, found in power distribution systems and motor drives, are distributed elements whose lengths may by far exceed the operating wavelength. They can be modeled as multi-conductor transmission lines, where many frequency-dependent characteristics including per unit length (p.u.l.) parameters, skin and proximity effect, dielectric losses, and transmission line propagation, reflections, and delay need to be appropriately accounted for $[75,76]$.

\subsubsection{Determination of Frequency-Dependent per Unit Length Parameters}

Typically, the first step in modeling cables is to determine their distribution or p.u.l. parameters. When cable material parameters and cross-sectional geometry are known, the p.u.l. parameters can be obtained using analytical formulas or numerical electromagnetic simulations.

Analytical formulas exist for a limited set of canonical cross-section geometries [77-80] or can be used in combination with cable cross-section partitioning for more general crosssection geometries [81,82]. Different numerical electromagnetic methods can also be used to extract the cable p.u.l. parameters, such as finite element method [80,83-89] or method of moments [90-92]. In cables designed primarily to carry high-frequency signals, the p.u.l. parameters are kept within strict tolerance levels during manufacture, which is not necessarily the case for power cables whose primary function is the distribution of power signals [79].

When the material and geometrical characteristics of the cable are not known, the p.u.l. parameters can also be extracted from measurements using an impedance meter [93,94], impedance analyzer $[29,80,95,96]$, vector network analyzer (VNA) [18,97-100], and combining the VNA measurements with time-domain reflectometry (TDR) [101] or impedance meter measurements [18] to accurately capture both DC, low, and high-frequency behavior.

\subsubsection{Cable Models Based on Lumped Segmentation of Transmission Line}

Equivalent circuits of multiconductor cables to be used in SPICE (Simulation Program with Integrated Circuit Emphasis) circuit simulations can be created using conventional lumped segmentation of transmission lines. Each segment is represented by an elementary cell containing the extracted p.u.l. RLGC parameters to model the transmission line that may have an additional RL ladder network to model for frequency-dependent skin and proximity effects, and an additional RC ladder network to model for frequency-dependent dielectric losses [29,80,82,93-96,101-104].

Approaches based on conventional lumped segmentation of transmission lines provide an adequate solution to the problem of mixed frequency/time simulations for short cables or approximate predictions of overvoltage transients. However, these methods lead to large circuit matrices, rendering the simulations inefficient and/or unstable especially for system-level EMC simulations including long cables [105,106].

\subsubsection{Cable Models Based on Matrix Transfer Functions}

An equivalent circuit of transmission lines can also be obtained based on matrix transfer functions that interrelate terminal voltage and current vectors. They can be further emulated in SPICE using modal decoupling and voltage/current controlled generators [105] or represented in a form of matrix rational function in terms of poles and residues either analytically [107], or using various numerical algorithms such as a vector-fitting algorithm [108-111], matrix-rational approximation method [106], or method of characteristics [112]. Additionally, more advanced methods, such as extraction of the propagation delay in the method of characteristics [113], delayed vector fitting (DVF) [114], or multivariate orthonormal vector fitting (MOVF) $[115,116]$ can also be used. These matrix rational function techniques are suited to generate state-space models and synthesize equivalent circuits, which can be embedded into conventional SPICE solvers by using lumped RLC elements $[63,108,117]$, Laplace elements $[17,105]$, and/or controlled sources $[76,105,118]$. 
The behavioral modeling procedure for long multiconductor power cables presented in [17] starts with measurements of the DC resistances of the cable and of its frequencydependent admittance matrix up to the highest frequency of interest using a VNA. Rational function interpolation and passivity enforcement are used next to create an analytic representation of the tabulated measured data [108-110]. Finally, a SPICE equivalent circuit of the measured cable is produced by translating the rational function representation into the circuit domain $[76,105,117]$. This approach provides stable, causal, and passive equivalent circuits of multiconductor cables that can be used in both time- and frequency-domain SPICE simulations. An extension of this method is introduced in [18] to obtain lengthscalable multi-conductor cable models by using modal decomposition $[119,120]$, extracting the p.u.l. parameters from the measured admittance matrix, and by taking advantage of the rotational symmetries of the cable, which in turn result in reduced equivalent circuits that speed up the SPICE simulations of long multiconductor power cables (three- and four-conductor shielded cables of $150 \mathrm{~m}$ length were modeled). This method is used for creating models of multi-conductor cables in this paper.

\subsection{Motor Modeling}

High-frequency modeling of induction machines plays an important role in investigating motor drive electromagnetic interference issues such as stator winding reflected-wave overvoltage and bearing discharging current [121].

Physical modeling of motors utilizes electromagnetic field analysis based on 2-D or 3-D FEM to create the equivalent circuits [122-126]. This methodology requires complete geometry and material information and it enables a detailed EMC analysis and design of the motor itself.

Behavioral modeling needs real motor measurements to construct the equivalent circuit that reproduces the motor impedances. These impedances are usually measured using an impedance analyzer on a motor in several connection schemes (typically in common and differential modes). The circuit parameters can then be extracted from the measurements using either pre-defined equivalent circuit topologies that emulate the physical behavior of the motors $[29,93,95,102,121,127-134]$ or more general circuit topologies based on rational function approximations [135,136] and vector fitting algorithm [17,19,137,138]. A combination of FEM and behavioral modeling may also be used to improve and fine-tune the model parameters [139].

It is useful to create equivalent circuit models of various motors, which can then be used to assess the conducted noise in the full converter system for different loads.

The behavioral motor model used in this paper is created by a parallel connection of a high-frequency motor model based on measurements of a standstill motor [19] and a low-frequency model capturing the operation condition of the motor [23]. A high pass filter placed in front of the high-frequency model ensures that depending on the frequency of excitation the correct motor model is used.

\subsection{Interconnects, $P C B$, and Housing}

From the EMC theory point of view, all low frequency (LF) coupling mechanisms (galvanic, capacitive, and inductive coupling) are present in a power converter system and must be adequately taken into account $[1,2]$.

In the EMC analysis of real applications, the influence of PCB- and interconnects design is sometimes overlooked. It is however very important to include the abovedescribed parasitic effects in the system level circuits $[12,13,53,140]$, as will be demonstrated later in Section 3.3. Although the extraction of equivalent circuits from 3-D models of interconnects is quite a complex and time-consuming task, careful preparation of the CAD data can significantly accelerate the modeling so that it can be integrated into the EMC analysis process. For that purpose, the following features are expected from commercial design tools: 
- import of the manufacturer CAD data with the automated placement of component models, ports, and terminals;

- extraction of models with a large number of ports $(>100)$;

- extraction of passive, broadband models which are accurate in a preselected frequency range;

- Creating a standard, SPICE-compatible output model, suitable for time- and frequencydomain system level simulations.

Presently, there are several commercial tools, allowing a full data process chain from CAD import to the extraction of the wideband equivalent circuit. Tools like ANSYS Q3D Extractor [141] or Dassault CST studio suite (3D/PCB) [142] implement the full design chain described above, are easy to use and validated in a variety of applications by a large user community.

\subsection{HF Capacitor and Resistor Models}

Capacitors, together with inductors, are essential components of any filter design. Contrary to the complexity of the inductor modeling techniques (see Section 2.1), the impedance curves of nearly all types of capacitors can be accurately represented by a simple series RLC equivalent circuit. The RLC values can be obtained from measurements either directly using hardware (Impedance- or Vector Network Analyzer) or software fitting tools (e.g., Matlab Zfit [143]).

Analysis of impedance curves of different capacitors can be very helpful in the capacitor selection procedure, especially if certain resonances have to be damped by the appropriate selection of the filter capacitors.

\subsection{Power Semiconductor Models}

In most PE applications, the power semiconductors are operated in switching mode and their switching waveforms are the main EMC noise source. The spectrum of this noise source is determined by the applied control scheme that determines the switching frequency of the semiconductors, and by the switch-on/switch-off waveforms of the switching devices, which depend on the type of semiconductor (IGBT, MOSFET, BJT, WBG semiconductors $[9,10])$. The EMI noise spectrum increases with increasing switching frequency and with reduced turn-on and turn-off time (for frequencies above the inverse switching time). Due to the dominant role of semiconductors in EMC noise creation, accurate semiconductor models are needed in EMC simulations, that capture switching waveforms of controlled commutations and reverse recovery of free-wheeling diodes for spontaneous commutation.

A detailed analysis of semiconductor modeling techniques is beyond the scope of this paper, however, in the following we give a short overview of power semiconductor models used in system-level EMC simulations. Modeling of power diodes [144-147], MOSFETs [148,149], and BJTs [150] is well established, therefore, numerous models are readily available either in libraries of SPICE simulation tools (e.g., SIMetrix [151], LTSpice [152]) or on the web pages of most manufacturers. This does not seem to be the case for IGBT models. A detailed overview of the modeling techniques and different complexity levels of IGBT models can be found in $[153,154]$. Although several physical and behavioral models of the coupled MOSFET-BJT structure of an IGBT device are presented in the literature [145,146,155-167], the parameter extraction procedures ask for simultaneous fitting to both static and dynamic device measurement data, which makes the modeling of IGBTs a rather complex task even for major manufacturers. Quite a few of them provide models of some IGBT devices (e.g., $[165,166])$ but the accuracy and stability of these models differ and the selection of an appropriate model for system level EMC simulations is still challenging.

\subsection{LISN and Noise Detector Modelling}

The line impedance stabilized network (LISN) is a low pass filter device, connected between the mains and device under test (DUT). Application of a LISN in a test setup serves 
two purposes: it filters out the HF electrical noise from the grid and it provides a test port for EMC conducted emission measurements. A standard LISN must provide $50 \Omega$ impedance between each line and the common ground in the frequency range $150 \mathrm{kHz}-30 \mathrm{MHz}$.

A typical circuit diagram of one phase leg of a CISPR-16-1-2 [5] compatible LISN is shown in Figure 1. Depending on the power level and manufacturer, the values of filter components and the number of low-pass filter stages can vary but the circuit diagram from Figure 1 is a good starting point for creating a LISN equivalent circuit in system level EMC simulations.

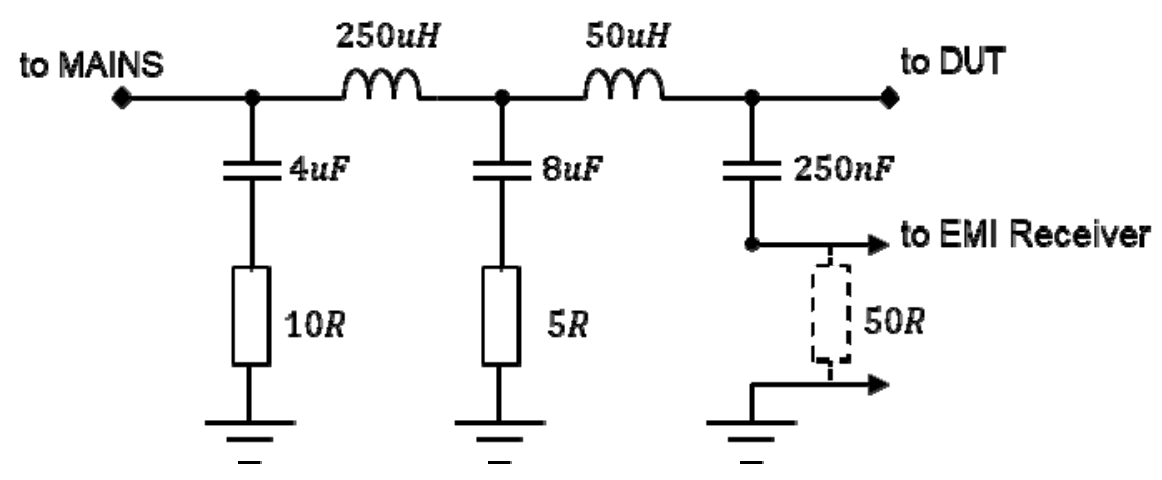

Figure 1. A CISPR-16-1-2 compatible one phase leg LISN circuit diagram [5].

EMC standards are referring to the EMC noise using two types of noise detectors: average $(\mathrm{AV})$ and quasi-peak $(\mathrm{QP})$. These noise detectors are implemented in a special type of spectrum analyzers called EMI receivers. Since system level EMC simulations are usually evaluated/compared with measured EMI noise, there is a need for having a software implementation of QP and AV detectors based on simulation data. The easiest way to obtain a QP or AV spectrum is the use of postprocessing routines. A digital time-domain data processing methodology with the emulation of $\mathrm{AV}, \mathrm{QP}$, etc. detectors can be found in [168] and has been used to post-process the simulations shown here.

\section{System Level EMC Simulation and Analysis: Voltage-Source Inverter Driving a Motor}

In this section, we analyze measured and simulated EMC noise spectra of an industrial power converter. The power converter is a $75 \mathrm{~kW}, 400 \mathrm{~V}$ three-phase variable speed drive with a two-level inverter topology and an input diode rectifier. The converter is connected via a long (10-200 m) shielded power cable to a $45 \mathrm{~kW}$ induction motor. The measurements of conducted EMC noise are performed in an EMC lab according to the norms specified in [3-5]. The simulation model of the EMC setup is created by combining the component models reviewed in Section 2 into a full system model in SPICE software [151]. We show the accuracy of the model in predicting the measured conducted EMC noise. Then we analyze and simplify the system model in order to identify the main noise propagation paths and the best noise filtering options. We found a dominant impact of the motor cable on the measured EMC noise as well as of the couplings caused by the interconnects.

\subsection{Build-Up and Validation of System Level EMC Simulation}

The schematic of the EMC setup is shown in Figure 2. The required component models have been discussed in the previous section. The common mode choke is realized by placing three nanocrystalline magnetic cores around the three-phase input and it is modeled using the physical equivalent circuit presented in [15], with parameters extracted from impedance measurements. The two identical DC reactors are modeled with a behavioral model created by applying vector fitting to the measured impedance [108]. 


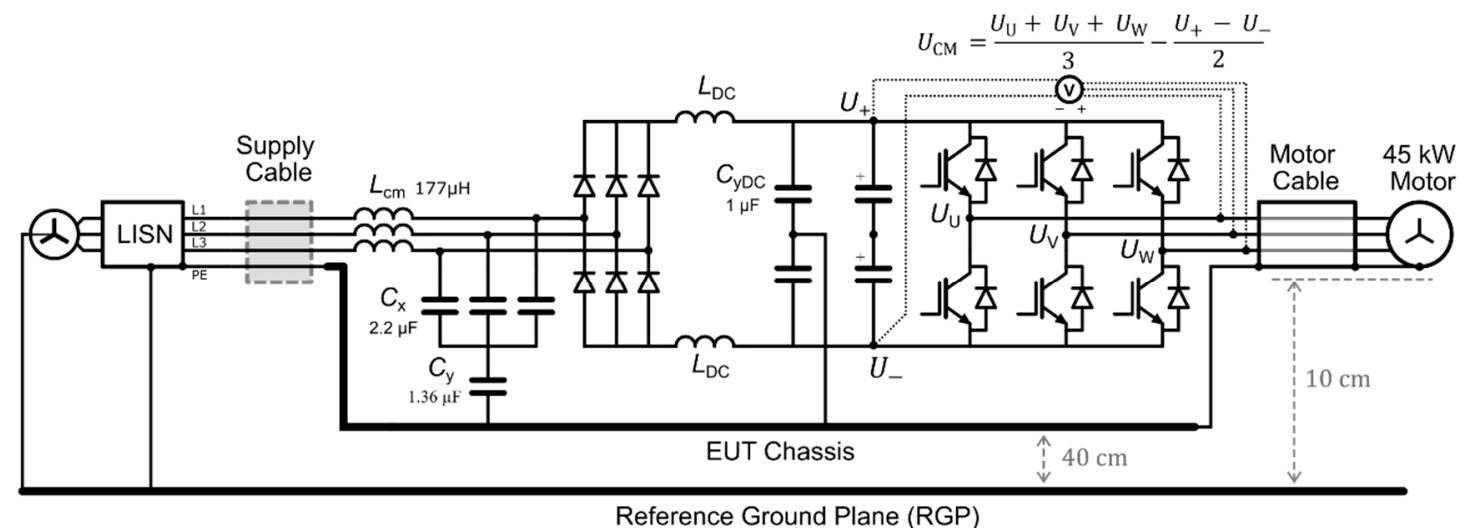

Figure 2. Simplified schematic representation of the EMC setup. Low-frequency values of filter components are specified, but corresponding EMC models are more complex as discussed in Section 2. The corresponding CM-circuit is derived in Section 3.2.

The model of the shielded motor cable is based on VNA measurements and created using vector fitting [17]. Models of the same cable with different lengths are obtained by first extracting the p.u.l. parameters of the cable which are then used to create the equivalent circuit of the same cable for any length [18].

The voltages across the IGBTs in the inverter power module with an average switching frequency of $4 \mathrm{kHz}$ are the main noise source of the drive. The IGBTs were modeled using physical behavioral models obtained from the manufacturer $[165,166]$. The actual equipment under test (EUT) uses a complex vector control algorithm to determine the switching pattern. Given that the average switching frequency of $4 \mathrm{kHz}$ is well below the EMC band of conducted emissions starting at $150 \mathrm{kHz}$, the exact switching pattern has only a minor impact on EMC noise in stationary operation. Therefore, a simplified scalar control scheme based on pulse width modulation is used in the simulations to approximate the real behavior.

Interconnects between the components are not ideal shorts and introduce relevant parasitic couplings that need to be included as was discussed in Section 2.4. Parasitic effects of wires, busbars, and the metal chassis are included in the full three-phase simulation by extracting an RLGC equivalent SPICE circuit of interconnects and housing using a quasi-static field solver based on the method of moments (MoM [141]) as described in Section 2.4. The simplified 3D model of the structure is shown in Figure 3. The extracted black-box model has 69 ports and includes parasitic capacitances, coupled inductances, and resistances. Instead of connecting the components of the schematic shown in Figure 2 by ideal shorts, they are then connected at the corresponding ports of the extracted SPICE circuit. The compact broadband model of interconnects and housing is not shown explicitly in the schematic of Figure 2 for better readability but is an important part of the full three-phase circuit model.

Figure 4a shows the measured EMC noise at the LISN for all three phases, labeled L1, L2, and L3 in the setup shown in Figure 2. The EMC noise shows repetitive resonances as functions of frequency that exist due to wave resonances in the motor cable that occur at certain ratios of wavelength to cable length, as we will discuss in more detail in Section 3.3. The schematic shown in Figure 2 does not include any auxiliary power circuit that powers fans or control and gate circuits. These auxiliary circuits also include switch mode power supplies with high switching frequency, however, they process much lower powers. Figure $4 \mathrm{~b}$ shows that for the analyzed converter, the contribution of these auxiliary circuits to conducted noise emissions is small. The red curve in Figure $4 \mathrm{~b}$ is the phase noise for normal operation, as also shown in Figure 4a. For comparison, the black curve in Figure $4 \mathrm{~b}$ shows the EMC noise when only the auxiliary power is turned on, while the inverter is not switching, and the motor is at a standstill. The noise stemming from the auxiliary supply alone has a minor contribution to the total EMC noise and only becomes 
relevant for frequencies above $4 \mathrm{MHz}$, where for the setup shown, the noise is well below the norm. Therefore, the auxiliary power circuit is not included in the simulation, and simulation results above $4 \mathrm{MHz}$ are not accurate.

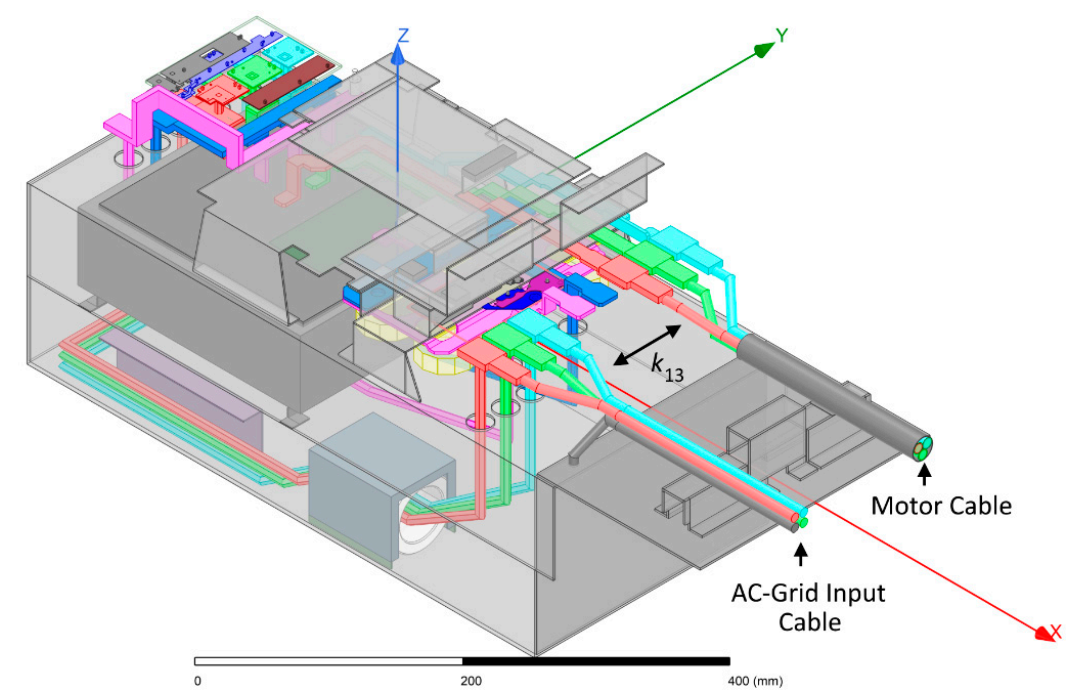

Figure 3. 3D model of the chassis and busbar geometry in the prototype for parasitic RLGC extraction (MoM) [141].

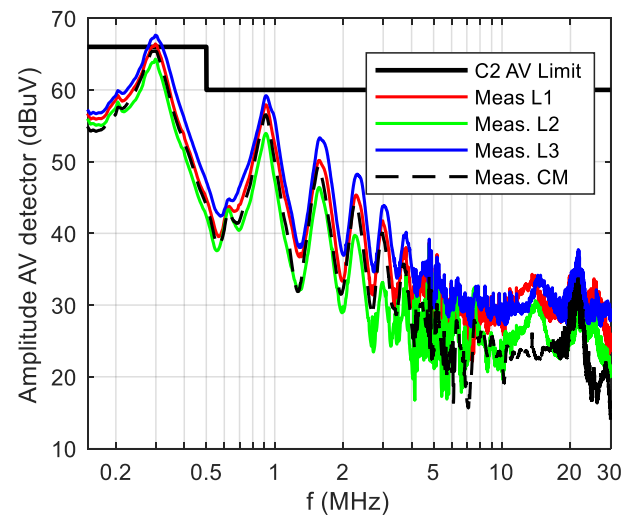

(a)

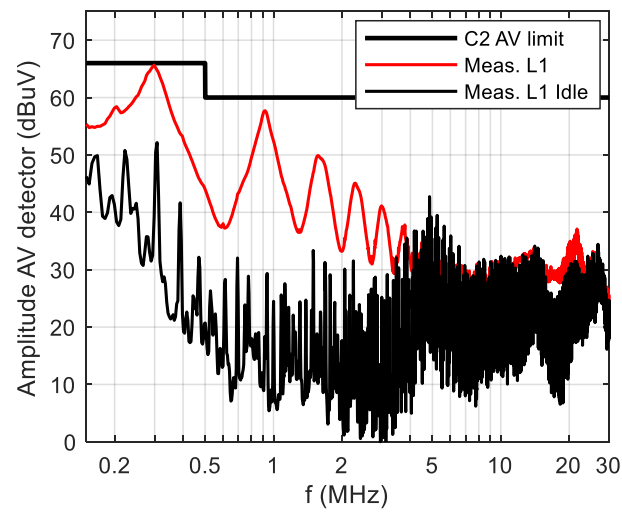

(b)

Figure 4. Measured average detected grid noise of all three phases L1, L2, and L3 with a $100 \mathrm{~m}$ motor cable $\left(16 \mathrm{~mm}^{2}\right)$ during (a) normal operation with motor rotation (b) comparison between the noise of normal operation and the motor at standstill with no switching at inverter (idle).

\subsection{Common Mode Equivalent Circuit and Impact of Interconnects on EMI Noise}

For EMC analysis it is useful to separate the phase noise in its common mode (CM) and differential mode (DM) components. CM current flows between the power conversion system and ground, while current flowing between the power lines is denoted as DM noise. As indicated in Figure 2 with the line voltages at the LISN denoted as $U_{L i}, i=1,2,3$, the $C M$ voltage $U_{C M}$ and differential mode voltages $U_{D M i}$ at the LISN can be defined as:

$$
U_{C M}=\frac{U_{L 1}+U_{L 2}+U_{L 3}}{3} ; U_{D M i}=U_{L i}-U_{C M} ; i=1,2,3 .
$$

In measurements, the transformation from phase noise to common mode and differential mode noise is done using a CM/DM noise separator $[169,170]$. The measurement results shown in Figure 5a reveal that the EMC noise is dominated by the common mode noise, which will be the focus of the EMC analysis in this paper. Figure $5 b$ shows the CM 
and DM noise obtained by postprocessing of time-domain simulations of the full setup. Simulated and measured EMC curves are in excellent agreement up to $4 \mathrm{MHz}$. For higher frequencies, the EMC noise is very low, and the auxiliary power supply noise becomes significant, which explains the deviation between simulations and measurements. As explained in Section 2.6, the dominant EMC noise sources of the converter shown in Figure 2 are the switching waveforms of the IGBTs in the inverter. The propagation of differential mode noise from the inverter towards the input (AC grid side) is well suppressed by the electrolytic DC capacitors, however, the DC capacitor cannot filter CM noise. The main reasons why measurements still show significant DM noise at the AC grid side are the noise mixing between $\mathrm{CM}$ and DM within the diode rectifier [20] and parasitic magnetic couplings from the noisy load side to the input side [171], which will be described later in Section 3.3.

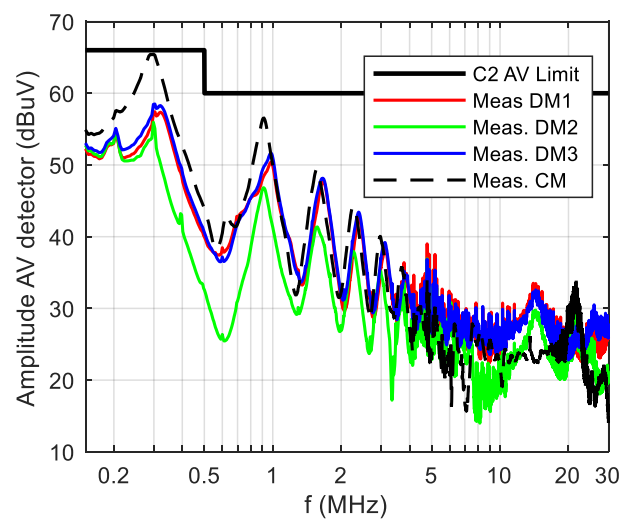

(a)

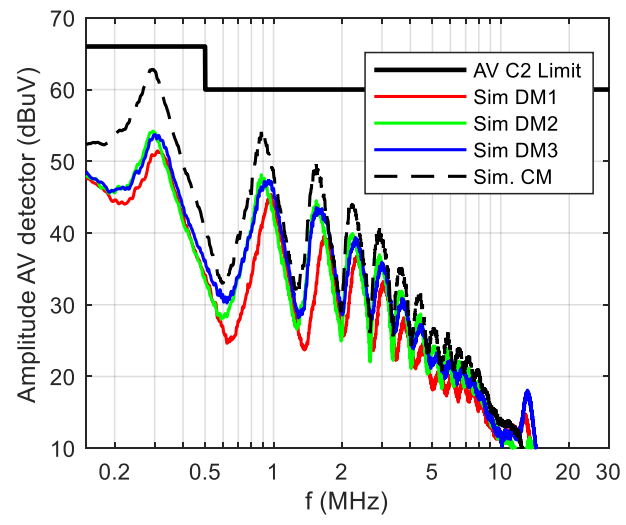

(b)

Figure 5. Average detector noise level of differential mode and common mode noise emissions as defined in Equation (1) with a $100 \mathrm{~m}$ motor cable $\left(16 \mathrm{~mm}^{2}\right)$ (a) Measurement with CM/DM LISN separator. (b) Simulation results.

The propagation of the $\mathrm{CM}$ noise can be described by the equivalent circuit shown in Figure 6. Most of the impedances shown in the CM circuit of Figure 6 are the $\mathrm{CM}$ impedances of the components shown in the three-phase circuit of Figure 2. The frequencydependent $\mathrm{CM}$ impedances are shown in Figure $7 \mathrm{a}$ and they are accurately reproduced by the circuit models. The impact of the diode rectifier either as a $\mathrm{CM}$ noise source or $\mathrm{CM}$ impedance is neglected in the CM circuit of Figure 6, while the HF noise introduced by the switching of the DC voltage in the inverter is represented as a fixed voltage noise source $U_{\mathrm{cm}}$. As indicated in Figure 2, the noise source $U_{\mathrm{cm}}$ is the voltage difference between the DC bus midpoint and the average of the three output voltages, and it is determined only once, using a time-domain simulation of the full three-phase circuit (which uses accurate semiconductor models). The frequency spectrum of $U_{\mathrm{cm}}$ is shown in Figure $7 \mathrm{~b}$.

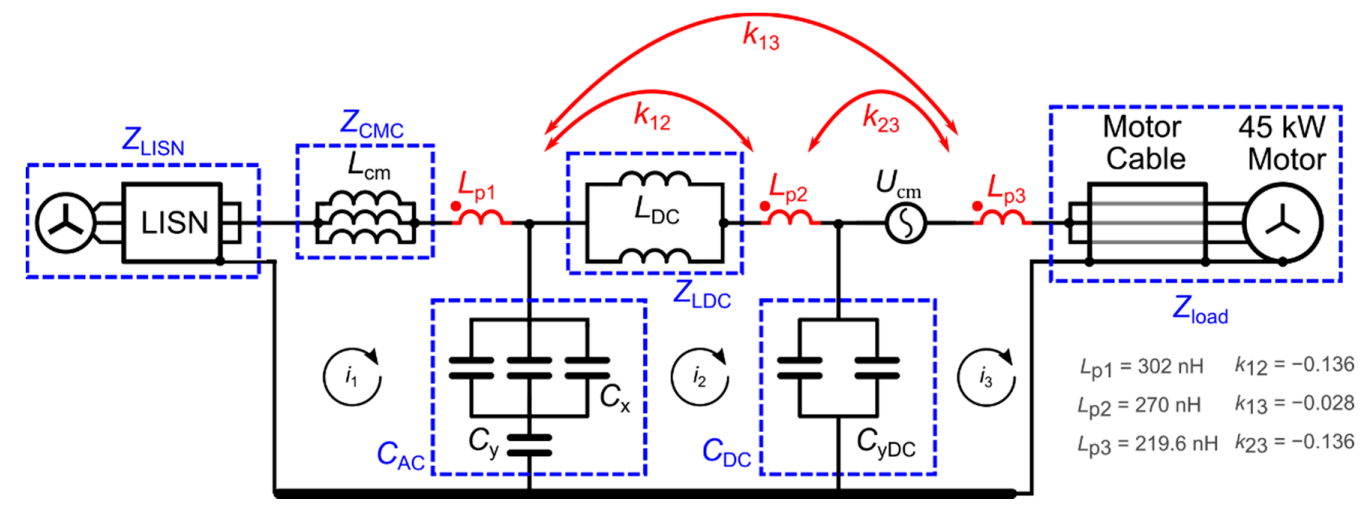

Figure 6. The equivalent CM circuit of the converter including magnetic parasitic couplings. The 3-phase circuit is shown in Figure 2. 


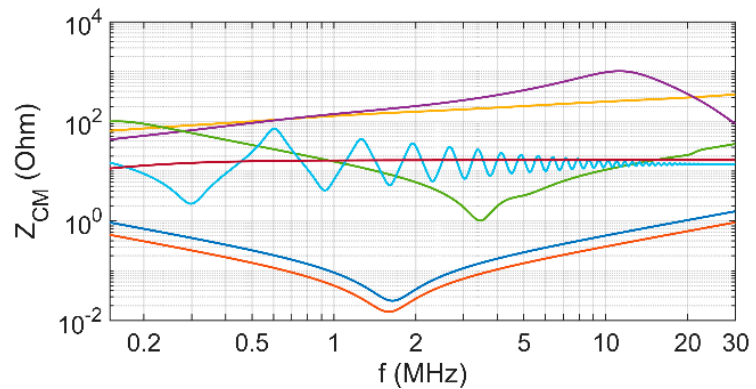

(a)

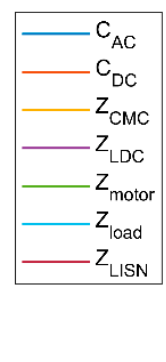

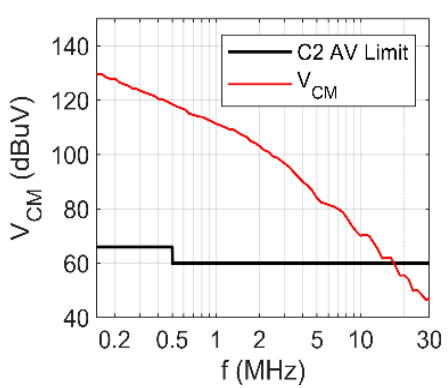

(b)

Figure 7. (a) The circuit impedances of the equivalent CM circuit shown in Figure 6 with a $100 \mathrm{~m}$ motor cable $\left(16 \mathrm{~mm}^{2}\right) .(\mathbf{b})$ The spectrum of the CM noise source (using AVG detector). The corresponding EMC noise is shown in Figure 5.

The parasitic CM loop inductances $L_{\mathrm{p} 1}, L_{\mathrm{p} 2}, L_{\mathrm{p} 3}$ and their mutual couplings $k_{12}, k_{13}, k_{23}$ capture the most relevant coupling mechanism of the interconnects and housing shown in Figure 3 and they can be directly extracted by defining the corresponding CM current paths in the quasi-static field solver [141] using matrix reduction which corresponds to a parallel connection of the AC-phases and DC buses. The loop inductances $L_{\mathrm{p} 1}$ and $L_{\mathrm{p} 3}$ and their coupling coefficient $k_{13}$ quantify the important magnetic coupling between the noisy output of the converter on the load side and the quiet input of the converter on the AC-grid side. As indicated in Figure 3, this coupling is introduced by the pigtails of the input and output cables that are close to each other, run in parallel, and do not have any shielding. Why are the other types of parasitics introduced by the interconnects less important? Parasitic capacitances between different interconnects and between interconnects and chassis turn out to have little impact on CM noise propagation, due to the dominant shunt capacitances $C_{\mathrm{AC}}$ on the grid side, $C_{\mathrm{DC}}$ on the DC link, and the effective cable capacitance between the conductors of the motor cable and their grounded shield. Furthermore, resistances of the interconnects are small compared to the other impedances within each loop namely $Z_{\text {LISN }}$ $+Z_{\mathrm{CMC}}, Z_{\mathrm{LDC}}$, or $Z_{\text {load }}$. In contrast, the magnetic coupling between the different current loops, which is modeled by the parasitic loop inductances $L_{\mathrm{p} 1}, L_{\mathrm{p} 2}, L_{\mathrm{p} 3}$ with their mutual coupling factors $k_{12}, k_{13}, k_{23}$ is highly relevant, because the induced voltages bypass the capacitive filters $C_{A C}$ and $C_{D C}$. It turns out that the most important coupling is the one between the load loop with its high noise current between $i_{3}$ and the grid loop with its low noise current $i_{1}$.

The CM circuit shown in Figure 6 consists of three loops. The first loop contains the CM impedances on the grid side: LISN $\left(Z_{\text {LISN }}\right)$, common mode choke $\left(Z_{C M C}\right)$, and the $A C$ side capacitance $C_{A C}$ which consists of a series connection of $X$ and $Y$ capacitors. The loop current $i_{1}$ is subject to the EMC norms of the LISN side. The second loop consists of $C_{\mathrm{AC}}$, the DC-reactors $\left(Z_{\mathrm{LDC}}\right)$, and the DC-Y-capacitors $C_{\mathrm{DC}}$. As already stated above, the impact of the diode rectifier on the CM noise in the EMC range is neglected here. The third loop contains $C_{\mathrm{DC}}$, the $\mathrm{CM}$ voltage noise source $U_{\mathrm{cm}}$, and the load impedance $Z_{\text {load }}$ given by the CM impedance of the cable terminated with the motor. The loop current $i_{3}$ is by far the largest CM current in the system and its propagation to the LISN is filtered by the CLC filter formed by $C_{\mathrm{DC}}, Z_{\mathrm{LDC}}, C_{\mathrm{AC}}$. However, the magnetic couplings, most importantly $k_{13}$, bypass this filter.

The simple structure of the CM circuit helps to understand the noise propagation, furthermore, it is a linear circuit (if common mode choke and DC reactors are approximated by linear broadband models) which allows one to apply frequency-domain analysis, which is much faster than time-domain analysis.

The propagation of CM noise is assessed using the equivalent circuit shown in Figure 6 and the results are shown in Figure 8. As a validation of the simulation models, we show that the measured noise (curve (a) in Figure 8) is accurately predicted by time-domain 
simulations (curve (b) in Figure 8) using the three-phase circuit of Figure 2. Equivalent results are obtained by frequency-domain simulations (curve (c) in Figure 8) using the common mode circuit of Figure 6. By varying the three mutual coupling factors in the common mode circuit of Figure 6, the relative importance of the different couplings is analyzed. In the simulations, the coupling factors are simple parameters that can easily be changed. In the physical setup, the inductive couplings between the current loops depend on the layout of the interconnects and can be reduced by minimizing the area enclosed by the current loops, by increasing the distance between the loops, or by introducing electromagnetic shields. It is found that the coupling factor $k_{13}$ between loops 3 and 1 has the biggest impact. In fact, as shown by curve (d) in Figure 8, if the coupling between the input and output loops is set to zero $k_{13}=0$ (all other parameters stay the same), the grid side noise is reduced significantly below the norm limit. The load side loop (between inverter and load) has the largest EMI noise current, which explains the relevance of even a small magnetic coupling between output and input.

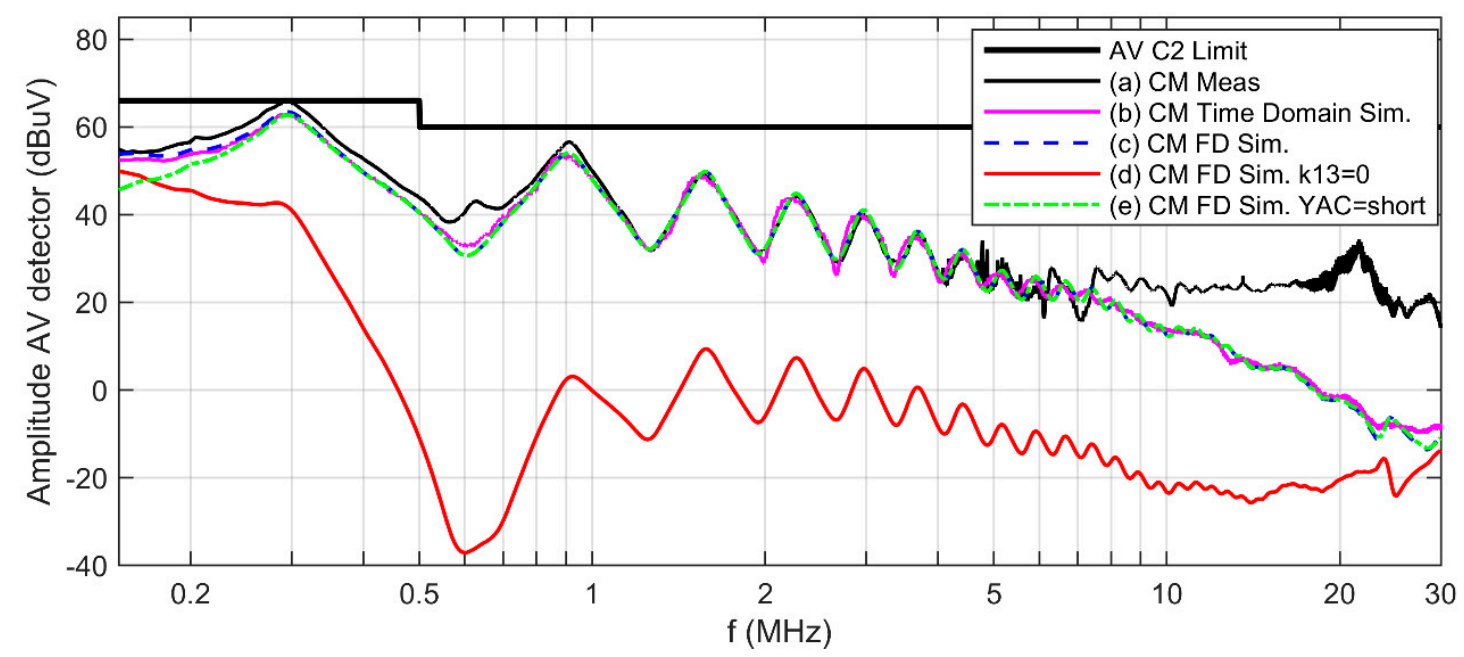

Figure 8. Simulated and measured conducted emissions of CM noise. Simulation (b) used the full three-phase circuit shown in Figure 2, simulations (c)-(e) used the common mode circuit shown in Figure 6 with frequency-domain (FD) solver. The setup uses a $100 \mathrm{~m}$ motor cable $\left(16 \mathrm{~mm}^{2}\right)$.

In contrast, an increase of the AC-side capacitance does not reduce the $\mathrm{CM}$ noise. As shown by curve (e) in Figure 8, the noise level remains almost unchanged (except for a small reduction at $150 \mathrm{kHz}$ ) when the filter capacitance $C_{\mathrm{AC}}$ on the grid side is shorted completely but the magnetic couplings are present. This finding confirms that the grid side CM noise is mainly caused by the induced voltage source in the grid side current loop. In the presence of the induced voltage, the current on the grid side is most effectively suppressed by a large impedance within the grid side loop, which is achieved by placing a large $C M$ choke impedance $Z_{C M C} \gg Z_{L I S N}+Z_{C A C}$ see Figure $7 a$. Unfortunately, among the EMC filter components, the $\mathrm{CM}$ choke is the largest and most expensive component. Other CM filter options will be discussed in Section 4.

\subsection{Impact of Cable Characteristics on EMI Noise}

In this section, we show that the prominent maxima in the EMC noise measured at the LISN are caused by cable resonances and we discuss how these maxima depend on the length and the type of the motor cable. As shown in Figure 7, the load impedance $Z_{\text {load }}$ is much larger than the impedance of the $C_{Y}$ caps at the DC link, called $C_{\mathrm{DC}}$ in Figure 7. Therefore, the current $i_{3}$ in the output loop is largest at the minima of the load impedance $Z_{\text {load }}$ (or maxima of its admittance $Y_{\text {load }}$ ). Furthermore, by comparing the impedances $Z_{\text {motor }}$ of the motor alone, with the load impedance $Z_{\text {load }}$ given by the CM impedance of the cable terminated with the motor, we notice that resonances of the load stem from 
the cable resonances. The measured noise at the LISN is determined by the current $i_{1}$ in the input loop. According to the circuit shown in Figure 6, the noise can propagate from the noisy output to the input either by conduction from output to DC link to input, or by the inductive coupling between the loop inductances. As we will see in the next section, the inductive coupling dominates the noise propagation. For both coupling paths, the EMC noise measured at the LISN shows the same maxima as the output noise (although with lower amplitude) and these maxima are essentially determined by the motor cable. Accurate cable models are therefore essential for EMC simulations of the current setup.

In order to further analyze the impact of the motor cable on EMC noise, measurements and simulations with two different cable types and for different cable lengths were done. The results are shown in Figure 9. Figure 9a compares the load admittance of the two cables, both $30 \mathrm{~m}$ long, connected to the same $45 \mathrm{~kW}$ motor. Both motor cables are three-phase, shielded power cables, but one uses conductors with a cross section of $16 \mathrm{~mm}^{2}$ and the other with $70 \mathrm{~mm}^{2}$ [172] The load admittances of the two cables shown in Figure 9a have the same qualitative behavior as the load admittances with the periodic cable resonances as functions of frequency. However, due to the different cable cross section, the p.u.l. parameters are different, which causes a different characteristic cable impedance and propagation constant. The measured and simulated EMC noise when these cables are used in the EMC setup of Figure 2 is shown in Figure 9c. Note that the maxima of the load admittance coincide with the maxima of the conducted noise emissions.

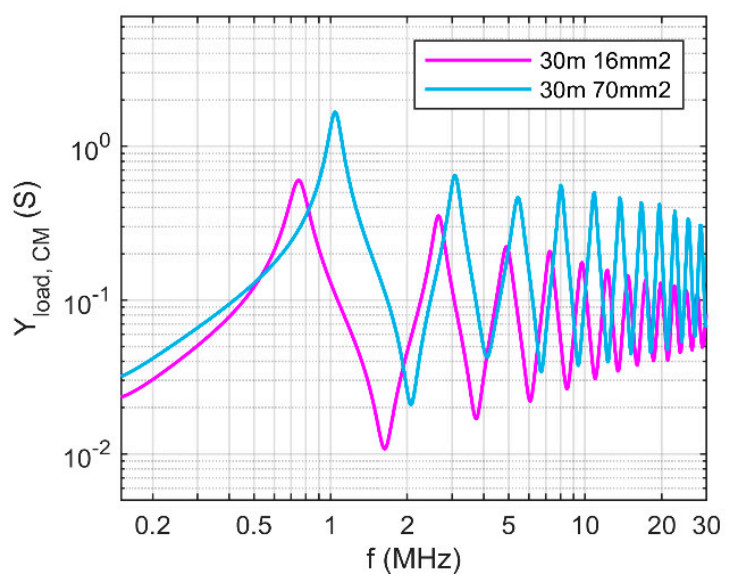

(a)

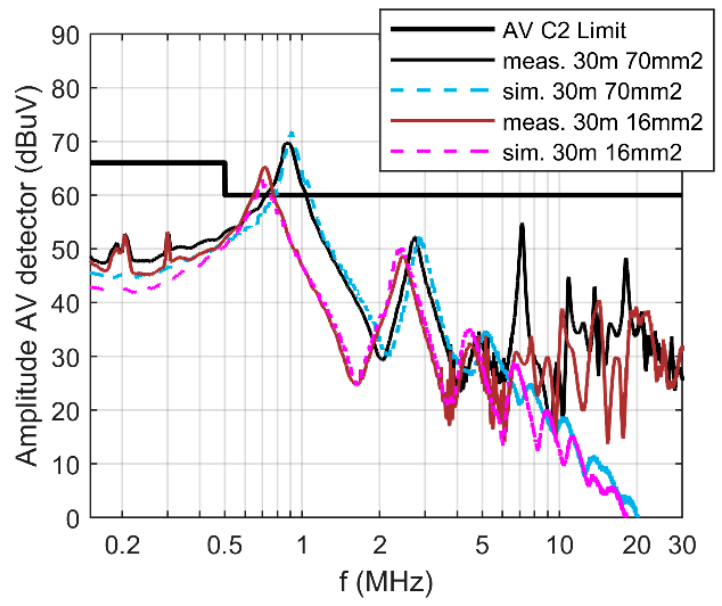

(c)

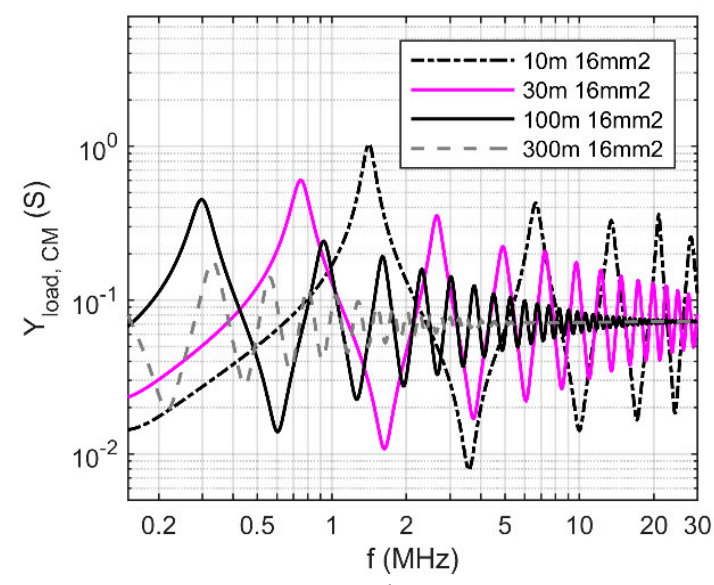

(b)

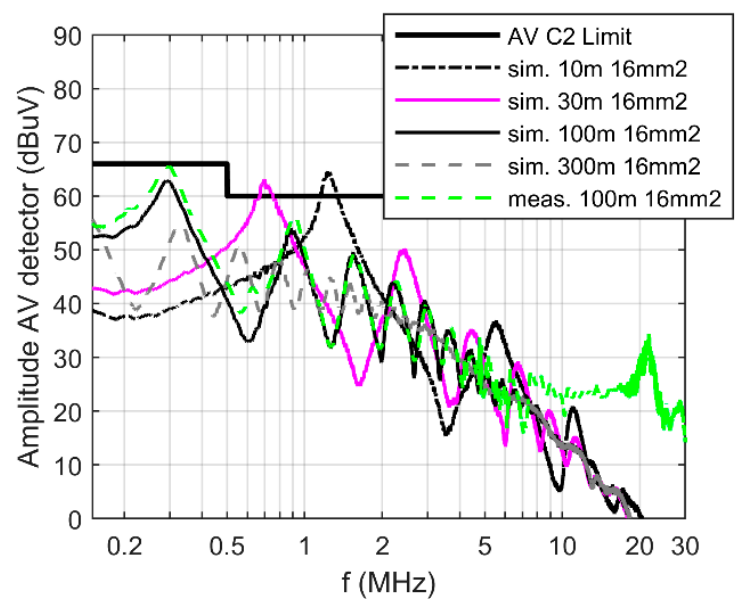

(d)

Figure 9. $\mathrm{CM}$ admittances $Y_{\text {load }}$ of different motor cables terminated with $45 \mathrm{~kW}$ motor are shown in subfigures (a,b). The $\mathrm{CM}$ noise emissions of the full system when using these cables are shown in subfigures $(\mathbf{c}, \mathbf{d})$. The impact of cable type (for the same cable length of $30 \mathrm{~m}$ ) on load admittance and noise emissions is shown in $(\mathbf{a}, \mathbf{c})$ and the impact of cable length (for same cable type with a $16 \mathrm{~mm}^{2}$ cross section of each conductor) is shown in (b,d). 
Figure 9c shows a good agreement between simulations and measurements up to about $5 \mathrm{MHz}$, however for higher frequencies the measured noise shows additional peaks that are not reproduced by the simulations. These peaks cannot be explained by the auxiliary supply alone but are most probably caused by coupling between the motor cable and the conductive ground plane present in the EMC setup [171]. Since the reference ground plane of the setup was not included in the simulation model, the effect is not reproduced in the simulation. In [171], the cable to ground coupling was analyzed and it was shown that changes in the cable layout relative to the ground plane can significantly affect the noise levels. However, the cable layout is currently not strictly specified in the EMC measurement standards, despite its large impact on the measured EMC noise.

Next, the impact of the cable length on the load admittance and EMC noise at the LISN is analyzed. Figure $9 \mathrm{~b}$ compares the load admittances of motor cables of the same cable type but of different lengths, all connected to the same $45 \mathrm{~kW}$ motor. With increasing length, the frequency spacing between successive maxima as well as the amplitude of the oscillations of the admittance is reduced. Both observations are well explained by the transmission line behavior of the cable. In the limit of an infinitely long cable, the load impedance would be given by the characteristic cable impedance that shows no oscillations.

Figure $9 \mathrm{~d}$ shows the EMC noise measured at the LISN, for the various cables shown in Figure 9b. Again, the resonances of the EMC noise stem from the cable resonances. The location of the first maximum in EMC noise (or load admittance) shown in Figure $9 \mathrm{~d}$ moves to lower frequencies as the cable length increases, while the amplitude stays roughly the same (or might even be higher for shorter cables). Interestingly, for the data shown in Figure 9d, the EMC norm is violated for the shorter cables (10 $\mathrm{m}$ and $30 \mathrm{~m})$ while the CM noise is below the limits prescribed by the norm for the longer cables (100 $\mathrm{m}$ and $300 \mathrm{~m}$ ). The large EMC noise for short cables contradicts the common belief that the EMC emissions increase with increasing cable length, and this finding is discussed and explained in Section 4 . Here we note that the length-scalable cable models are an effective and accurate tool to predict EMC noise emissions as shown by the good agreement between simulations and measurements in Figure 9.

\section{Discussion}

Before drawing general conclusions of this work and providing an outlook, in this section, we discuss two main findings of the EMC system simulations of the motor drive presented in Section 3.

The first finding was presented in Section 3.2 and concerns the impact of magnetic coupling on the filter performance of magnetic and capacitive filters. We showed that for the analyzed system, EMC noise is dominated by CM noise and we derived the equivalent circuit for CM noise propagation shown in Figure 6. Two main noise propagation paths were identified. The first noise path is the conventional galvanic noise propagation from the noise source at the inverter to the input side. This noise propagation is filtered by the CLCL-type filter formed by $C_{D C}, L_{D C}, C_{A C}, L_{C M}$. The CM choke $L_{C M}$ is larger and more expensive than the capacitors $C_{D C}, C_{A C}$ and its size could be reduced by increasing the capacitance $C_{A C}$ to ground. However, there is a second noise propagation path introduced by the coupled loop inductances $L_{p 1}, L_{p 2}, L_{p 3}$ in Figure 6, which represents the magnetic couplings between the interconnects. The coupling gives rise to an induced voltage $U_{\text {ind }}$ in the grid side current loop, which drives the grid current $i_{1}$. The induced voltage $U_{\text {ind }}=j \omega M i_{3}$, where $M=k_{13} \sqrt{L_{p 1} L_{p 3}}$ denotes the magnetic coupling between output and input loops and the dominant contribution was identified to be the cable connectors at the input and output of the convert as shown in Figure 3. The second noise propagation path dominates the emissions in the EMC frequency range. In fact, as shown in Figure 8 , even when replacing the capacitive filter $C_{A C}$ of the $C M$ circuit of Figure 6 by an ideal short, the emissions are not reduced. The emissions caused by the induced voltage are most effectively suppressed by a large impedance within the grid side loop, which is achieved by placing a large CM choke. What about other filter options for CM noise? In the presented 
setup, most of the EMC noise on the grid side is caused by the induced voltage between the motor side and the grid input side, and therefore an increase of the DC link impedance $Z_{\text {LDC }}$ value will have little effect on the grid noise. One could try to filter the noise on the load side, by placing a CM choke around the motor cable. However, the high CM current levels on the load side result in large losses in the core material and can cause saturation. Finally, the coupling factor $k_{13}$ could be lowered by introducing a shielding or by the improved layout of the busbar geometry. If these parasitic mitigation methods are not possible, the grid side common mode impedance must be kept high enough to limit the coupled noise below standard requirements.

The second finding of the EMC analysis that we discuss here concerns the dependence of noise emissions on the type and length of the motor cable as analyzed in Section 3.3. The maxima of EMC noise are caused by resonances of the long motor cable. The interesting finding was that in the analyzed system, the conducted EMC emissions are larger for cables with a length of $30 \mathrm{~m}$ than for cables of $100 \mathrm{~m}$ (or even $300 \mathrm{~m}$ ), which contradicts the common belief that emissions always increase with cable length. The common belief is based on the facts, that long cables have a larger capacitance to ground, leading to higher load admittance and, furthermore, the cable resonance occurs at a lower frequency where the noise source has a larger amplitude, see Figure $7 \mathrm{~b}$. The explanation for why the common belief is wrong here is based on a combination of EMC effects. First, while the noise source decreases in frequency as shown in Figure $7 b$, its propagation to the AC input is dominated by magnetic coupling (for the analyzed converter) leading to an induced voltage on the grid side $U_{\text {ind }}=j \omega M i_{3}$. This coupling is represented by the coupled loop inductances in circuit Figure 6. The magnetic coupling is more effective with increasing frequency, which improves noise propagation and compensates for the decrease of the noise source with increasing frequency. Furthermore, the cable resonances are better damped for longer cable lengths. Another aspect is that EMC norms are often stricter at higher frequencies (above $500 \mathrm{kHz}$ in Figure 9d) and the frequency of the cable resonance increases with reducing cable length. Similarly, for sufficiently long cables, the first resonance moves below this frequency and for even longer cables (e.g., for the $300 \mathrm{~m}$ cable shown in Figure 9), the first resonance of the cable admittance is below $150 \mathrm{kHz}$, which is the lower frequency bound of the frequency band " $\mathrm{B}$ " relevant for conducted emissions. However, in addition to the impact of the cable length on the EMC spectrum above $150 \mathrm{kHz}$, longer cables also increase capacitive currents in the low-frequency range (DC up to low harmonics of switching frequencies) due to increased parasitic cable capacitance. The increased CM currents must be considered in the design of the inductive CM filter components to avoid saturation, which relativizes the surprising finding that longer cables can lead to smaller EMC problems.

\section{Conclusions}

EMC simulations are shown to be an excellent tool to analyze EMC noise propagation and to assess the best filtering options. However, the setup of EMC simulations is a difficult task and requires experience. First, the relevant components need to be identified and modeled in the required detail. The relevant models are not limited to the power components of the converter, but also include the couplings introduced by interconnects, PCB and housing, as well as the external impedance of the converter at the input and output sides, such as the power cable, motor, including the LISN and noise detector. The models can be represented as SPICE circuits to allow including them into a circuit model for the EMC analysis of the full power converter. Often the circuit representation of the full EMC setup is rather complex, which can lead to long simulation times and sometimes even to numerical instability. Therefore, a simplification of the circuit is very beneficial, which also helps with better understanding the noise propagation. For example, the complex semiconductor models can be replaced by a fixed voltage source, representing the switching waveform, and/or by separately analyzing common and differential mode noise, which can often be analyzed by simpler circuits. The simplified circuit is often a linear circuit 
and can then be analyzed using much faster frequency-domain simulations. Conducted noise emissions of a $75 \mathrm{~kW}$ power converter driving a $45 \mathrm{~kW}$ motor were analyzed. Based on the simulations, the critical impedances within the system were identified, as well as the dominant noise propagation and the most efficient filter component and location. The conducted noise was found to be dominated by common mode noise in the studied system and a simplified CM circuit was derived. The layout of the interconnects and housing was shown to introduce parasitic magnetic couplings between output and input grounding loops formed by the EMC shunt capacitors and multiple common mode chokes are required to suppress the EMC noise caused by induced voltages. Sharp maxima in the conducted noise emissions were shown to be caused by cable resonances that can be accurately predicted as functions of type, length, and layout of the motor cable. An interesting finding was that in the analyzed system, the conducted EMC emissions were larger for cables with a length of $30 \mathrm{~m}$ than for cables of $100 \mathrm{~m}$ length or more, which contradicts the common belief that emissions always increase with cable length. All effects predicted and explained by the simulations were validated by measurements, and the close agreement between simulations and measurements underlines the benefit of simulation-based EMC analysis and filter design.

There are various possible continuations of this work. Having identified the detrimental effect of magnetic couplings between input and output, possibilities of an improved layout of the busbar geometry need to be assessed as well as other shielding options. Furthermore, in order to reduce the need for expensive common mode chokes, the benefit of an active EMC filter should be assessed [11]. Finally, while EMC simulations are a powerful tool to analyze conducted noise emissions and to design the required filter, further efforts are needed to build up similar simulation tools for radiated noise emissions.

Author Contributions: Conceptualization, B.W., S.S., V.F. and I.S.; methodology, B.W., S.S., V.F. and I.S.; software, B.W., S.S., V.F. and I.S.; validation, B.W., S.S., V.F.; formal analysis, B.W., S.S., V.F.; investigation, B.W., S.S., V.F. and I.S.; resources, B.W., S.S., V.F. and I.S.; data curation, B.W., S.S., V.F. and I.S.; writing —original draft preparation, B.W., S.S., V.F. and I.S.; writing-review and editing, B.W., V.F. and I.S.; visualization, B.W., V.F.; project administration, B.W., S.S. All authors have read and agreed to the published version of the manuscript.

Funding: This research received no external funding.

Institutional Review Board Statement: Not applicable.

Informed Consent Statement: Not applicable.

Conflicts of Interest: The authors declare no conflict of interest.

\section{References}

1. Paul, C. Introduction to Electromagnetic Compatibility; Wiley: Hoboken, NJ, USA, 2006.

2. Ott, H. Electromagnetic Compatibility Engineering; Wiley: Hoboken, NJ, USA, 2011.

3. EN/IEC 61800-3, Ed. 3.0, Adjustable Speed Electrical Power Drive Systems-Part 3: EMC Requirements and Specific Test Methods, 2017. IEC 61800-3:2017 I IEC Webstore I Electromagnetic Compatibility, EMC, Smart City, Pump, Motor, Water Management. Available online: https:/ / webstore.iec.ch/publication/31003 (accessed on 11 March 2021).

4. CISPR 11-Industrial Scientific and Medical Equipment-Radio-Frequency Disturbance Characteristics-Limits and Methods of Measurement. CISPR 11:2015 IIEC Webstore I Electromagnetic Compatibility, EMC, Smart City. Available online: https:// webstore.iec.ch/publication/22643 (accessed on 11 March 2021).

5. CISPR 16-1-2 Specification for Radio Disturbance and Immunity Measuring Apparatus and Methods-Part 1-2: Radio Disturbance and Immunity Measuring Apparatus-Measuring Apparatus, 2014. CISPR 16-1-2:2014+AMD1:2017 CSV IIEC Webstore I Electromagnetic Compatibility, EMC, Smart City. Available online: https:/ / webstore.iec.ch/publication/61924 (accessed on 11 March 2021).

6. Heldwein, M.L.; Kolar, J.W. Impact of EMC Filters on the Power Density of Modern Three-Phase PWM Converters. IEEE Trans. Power Electron. 2009, 24, 1577-1588. [CrossRef]

7. Mainali, K.; Oruganti, R. Conducted EMI mitigation techniques for switch-mode power converters: A survey. IEEE Trans. Power Electron. 2010, 25, 2344-2356. [CrossRef]

8. Kharanaq, F.A.; Emadi, A.; Bilgin, B. Modeling of Conducted Emissions for EMI Analysis of Power Converters: State-of-the-Art Review. IEEE Access 2020, 8, 189313-189325. [CrossRef] 
9. Gong, X.; Ferreira, J.A. Comparison and Reduction of Conducted EMI in SiC JFET and Si IGBT-Based Motor Drives. IEEE Trans. Power Electron. 2014, 29, 1757-1767. [CrossRef]

10. Han, D.; Li, S.; Wu, Y.; Choi, W.; Sarlioglu, B. Comparative Analysis on Conducted CM EMI Emission of Motor Drives: WBG Versus Si Devices. IEEE Trans. Ind. Electron. 2017, 64, 8353-8363. [CrossRef]

11. Wang, S.; Maillet, Y.Y.; Wang, F.; Boroyevich, D.; Burgos, R. Investigation of hybrid EMI filters for common-mode EMI suppression in a motor drive system. IEEE Trans. Power Electron. 2010, 25, 1034-1045. [CrossRef]

12. Wang, S.; Wang, F.; Maillet, Y.Y.; Lai, R.; Luo, F.; Boroyevich, D. Parasitic effects of grounding paths on common-mode EMI filter's performance in power electronics systems. IEEE Trans. Ind. Electron. 2010, 57, 3050-3059. [CrossRef]

13. Lai, J.S.; Huang, X.; Pepa, E.; Chen, S.; Nehl, T.W. Inverter EMI modeling and simulation methodologies. IEEE Trans. Ind. Electron. 2006, 53, 736-744. [CrossRef]

14. Stevanovic, I.; Skibin, S.; Masti, M.; Laitinen, M. Behavioral Modeling of Chokes for EMI Simulations in Power Electronics. IEEE Trans. Power Electron. 2013, 28, 695-705. [CrossRef]

15. Wunsch, B.; Skibin, S.; Forsstrom, V.; Christen, T. Broadband Modeling of Magnetic Components with Saturation and Hysteresis for Circuit Simulations of Power Converters. IEEE Trans. Magn. 2018, 54, 1-5. [CrossRef]

16. Wunsch, B.; Christen, T.; Skibin, S.; Forsstrom, V. Broadband Circuit Model of a Ferrite Core, Including Dimensional Resonance, Saturation, and Hysteresis. IEEE Trans. Magn. 2019, 55, 1-5. [CrossRef]

17. Stevanovic, I.; Wunsch, B.; Madonna, G.L.; Skibin, S. High-Frequency Behavioral Multiconductor Cable Modeling for EMI Simulations in Power Electronics. IEEE Trans. Ind. Inf. 2014, 10, 1392-1400. [CrossRef]

18. Wunsch, B.; Stevanovic, I.; Skibin, S. Length-Scalable Multiconductor Cable Modeling for EMI Simulations in Power Electronics. IEEE Trans. Power Electron. 2017, 32, 1908-1916. [CrossRef]

19. Stevanovic, I.; Wunsch, B.; Skibin, S. Behavioral High-Frequency Modeling of Electrical Motors. In Proceedings of the 2013 Twenty-Eighth Annual IEEE Applied Power Electronics Conference and Exposition (APEC), Long Beach, CA, USA, 17-21 March 2013; pp. 2547-2550.

20. Wunsch, B.; Drofenik, U.; Skibin, S.; Forsstrom, V. Impact of Diode-Rectifier on EMC-Noise Propagation and Filter Design in AC-Fed Motor Drives. In Proceedings of the IEEE International Symposium on Electromagnetic Compatibility, Washington, DC, USA, 7-11 August 2017; pp. 237-242. [CrossRef]

21. Skibinski, G.L.; Kerkman, R.J.; Schlegel, D. EMI emissions of modern PWM AC drives. IEEE Ind. Appl. Mag. 1999, 5, 47-80. [CrossRef]

22. Tallam, R.M.; Skibinski, G.L.; Shudarek, T.A.; Lukaszewski, R.A. Integrated differential-mode and common-mode filter to mitigate the effects of long motor leads on AC drives. IEEE Trans. Ind. Appl. 2011, 47, 2075-2083. [CrossRef]

23. Ran, L.; Gokani, S.; Clare, J.; Bradley, K.J.; Christopoulos, C. Conducted electromagnetic emissions in induction motor drive systems. I. Time domain analysis and identification of dominant modes. IEEE Trans. Power Electron. 1998, 13, 757-767. [CrossRef]

24. Ran, L.; Gokani, S.; Clare, J.; Bradley, K.J.; Christopoulos, C. Conducted electromagnetic emissions in induction motor drive systems. II. Frequency domain models. IEEE Trans. Power Electron. 1998, 13, 768-776. [CrossRef]

25. Ogasawara, S.; Akagi, H. Analysis and reduction of EMI conducted by a PWM inverter-fed AC motor drive system having long power cables. In Proceedings of the 2000 IEEE 31st Annual Power Electronics Specialists Conference. Conference Proceedings (Cat. No.00CH37018), Galway, Ireland, 18-23 June 2000; Volume 2, pp. 928-933.

26. Costa, F.; Vollaire, C.; Meuret, R. Modeling of conducted common mode perturbations in variable-speed drive systems. IEEE Trans. Electromagn. Compat. 2005, 47, 1012-1021. [CrossRef]

27. Gubia, E.; Sanchis, P.; Ursúa, A.; López, J.; Marroyo, L. Frequency domain model of conducted EMI in electrical drives. IEEE Power Electron. Lett. 2005, 3, 45-49. [CrossRef]

28. Moreau, M.; Idir, N.; Le Moigne, P. Modeling of conducted EMI in adjustable speed drives. IEEE Trans. Electromagn. Compat. 2009, 51, 665-672. [CrossRef]

29. Revol, B.; Roudet, J.; Schanen, J.L.; Loizelet, P. EMI study of three-phase inverter-fed motor drives. IEEE Trans. Ind. Appl. 2011, 47, 223-231. [CrossRef]

30. Bishnoi, H.; Mattavelli, P.; Boroyevich, D. Un-terminated common-mode EMI model of DC-fed motor drives. In Proceedings of the 2012 15th International Power Electronics and Motion Control Conference (EPE/PEMC), Novi Sad, Serbia, 4-6 September 2012; pp. DS2a.15-1-DS2a.15-8. [CrossRef]

31. Tan, W.; Cuellar, C.; Margueron, X.; Idir, N. A High Frequency Equivalent Circuit and Parameter Extraction Procedure for Common Mode Choke in the EMI Filter. IEEE Trans. Power Electron. 2013, 28, 1157-1166. [CrossRef]

32. Hague, B. The Principles of Electromagnetism Applied to Electrical Machines; Dover: New York, NY, USA, 1962.

33. Grover, F.W. Inductance Calculations: Working Formulas and Tables; Dover: New York, NY, USA, 2004.

34. Kazimierczuk, M.K. High-Frequency Magnetic Components; Wiley: Chichester, UK, 2009.

35. Massarini, A.; Kazimierczuk, M.K.; Grandi, G. Lumped parameter models for single- and multiple-layer inductors. In Proceedings of the 27th Annual IEEE Power Electronics Specialists Conference, Baveno, Italy, 23-27 June 1996; Volume 1, pp. $295-301$.

36. Wilcox, D.J.; Hurley, W.G.; Conlon, M. Calculation of self and mutual impedances between sections of transformer windings. IEE Proc. C Gener. Transm. Distrib. UK 1989, 136, 308. [CrossRef]

37. Wilcox, D.J.; Conlon, M.; Hurley, W.G. Calculation of self and mutual impedances for coils on ferromagnetic cores. IEE Proc. A Phys. Sci. Meas. Instrum. Manag. Educ. Rev. UK 1988, 135, 470. [CrossRef] 
38. Hurley, W.G.; Wilcox, D.J. Calculation of leakage inductance in transformer windings. IEEE Trans. Power Electron. 1994, 9, 121-126. [CrossRef]

39. Ouyang, Z.; Zhang, J.; Hurley, W.G. Calculation of Leakage Inductance for High-Frequency Transformers. IEEE Trans. Power Electron. 2015, 30, 5769-5775. [CrossRef]

40. Massarini, A.; Kazimierczuk, M.K. Self-capacitance of inductors. IEEE Trans. Power Electron. 1997, 12, 671-676. [CrossRef]

41. Grandi, G.; Kazimierczuk, M.K.; Massarini, A.; Reggiani, U. Stray capacitances of single-layer solenoid air-core inductors. IEEE Trans. Ind. Applicat. 1999, 35, 1162-1168. [CrossRef]

42. Pasko, S.W.; Kazimierczuk, M.K.; Grzesik, B. Self-Capacitance of Coupled Toroidal Inductors for EMI Filters. IEEE Trans. Electromagn. Compat. 2015, 57, 216-223. [CrossRef]

43. Ayachit, A.; Kazimierczuk, M.K. Self-Capacitance of Single-Layer Inductors with Separation Between Conductor Turns. IEEE Trans. Electromagn. Compat. 2017, 59, 1642-1645. [CrossRef]

44. Biela, J.; Kolar, J.W. Using Transformer Parasitics for Resonant Converters-A Review of the Calculation of the Stray Capacitance of Transformers. IEEE Trans. Ind. Applicat. 2008, 44, 223-233. [CrossRef]

45. Wu, B.; Zhang, X.; Liu, X.; He, C. An Analytical Model for Predicting the Self-Capacitance of Multi-Layer Circular-Section Induction Coils. IEEE Trans. Magn. 2018, 54, 1-7. [CrossRef]

46. de Freitas Gutierres, L.F.; Cardoso, G. Analytical Technique for Evaluating Stray Capacitances in Multiconductor Systems: Single-Layer Air-Core Inductors. IEEE Trans. Power Electron. 2018, 33, 6147-6158. [CrossRef]

47. Heldwein, M.L.; Dalessandro, L.; Kolar, J.W. The Three-Phase Common-Mode Inductor: Modeling and Design Issues. IEEE Trans. Ind. Electron. 2011, 58, 3264-3274. [CrossRef]

48. Kovacic, M.; Hanic, Z.; Stipetic, S.; Krishnamurthy, S.; Zarko, D. Analytical Wideband Model of a Common-Mode Choke. IEEE Trans. Power Electron. 2012, 27, 3173-3185. [CrossRef]

49. Henglin, C.; Zhaoming, Q.; Shaodong, Y.; Wolf, C. Finite-Element Modeling of Saturation Effect Excited by Differential-Mode Current in a Common-Mode Choke. IEEE Trans. Power Electron. 2009, 24, 873-877. [CrossRef]

50. Kovacic, M.; Stipetic, S.; Hanic, Z.; Zarko, D. Small-Signal Calculation of Common-Mode Choke Characteristics Using FiniteElement Method. IEEE Trans. Electromagn. Compat. 2015, 57, 93-101. [CrossRef]

51. Traub, F.; Wunsch, B.; Skibin, S. A high frequency model of toroidal chokes for EMC filtering. In Proceedings of the 2015 IEEE International Symposium on Electromagnetic Compatibility (EMC), Dresden, Germany, 16-22 August 2015; pp. 902-907.

52. Kovacevic, I.F.; Friedli, T.; Musing, A.M.; Kolar, J.W. Full PEEC Modeling of EMI Filter Inductors in the Frequency Domain. IEEE Trans. Magn. 2013, 49, 5248-5256. [CrossRef]

53. Kovacevic, I.F.; Friedli, T.; Musing, A.M.; Kolar, J.W. 3-D Electromagnetic Modeling of Parasitics and Mutual Coupling in EMI Filters. IEEE Trans. Power Electron. 2014, 29, 135-149. [CrossRef]

54. Liu, X.; Grassi, F.; Spadacini, G.; Pignari, S.A.; Trotti, F.; Mora, N.; Hirschi, W. Behavioral Modeling of Complex Magnetic Permeability With High-Order Debye Model and Equivalent Circuits. IEEE Trans. Electromagn. Compat. 2020, 1-9. [CrossRef]

55. Dominguez-Palacios, C.; Bernal, J.; Prats, M.M. Characterization of Common Mode Chokes at High Frequencies with Simple Measurements. IEEE Trans. Power Electron. 2018, 33, 3975-3987. [CrossRef]

56. Dominguez-Palacios, C.; Mendez, J.B.; Prats, M.A.M. Characterization of Three-Phase Common-Mode Chokes at High Frequencies. IEEE Trans. Power Electron. 2018, 33, 6471-6475. [CrossRef]

57. Dominguez-Palacios, C.; Gonzalez-Vizuete, P.; Martin-Prats, M.A.; Mendez, J.B. Smart Shielding Techniques for Common Mode Chokes in EMI Filters. IEEE Trans. Electromagn. Compat. 2019, 61, 1329-1336. [CrossRef]

58. González-Vizuete, P.; Domínguez-Palacios, C.; Bernal-Méndez, J.; Martín-Prats, M.A. Simple Setup for Measuring the Response to Differential Mode Noise of Common Mode Chokes. Electronics 2020, 9, 381. [CrossRef]

59. Kotny, J.-L.; Margueron, X.; Idir, N. High-Frequency Model of the Coupled Inductors Used in EMI Filters. IEEE Trans. Power Electron. 2012, 27, 2805-2812. [CrossRef]

60. Li, Z.; Pommerenke, D.; Shimoshio, Y. Common-mode and differential-mode analysis of common-mode chokes. In Proceedings of the 2003 IEEE Symposium on Electromagnetic Compatibility, Boston, MA, USA, 18-22 August 2003; Volume 1, pp. $384-387$.

61. Sánchez, A.M.; Pérez, A.; Regué, J.R.; Ribó, M.; Rodríguez-Cepeda, P.; Pajares, F.J. A Modal Model of Common-Mode Chokes for Conducted Interference Prediction. IEEE Trans. Electromagn. Compat. 2010, 52, 749-752. [CrossRef]

62. Nguyen, T.N.; Blanchette, H.F.; Wang, R. General Impedance Representation of Passive Devices Based on Measurement. IEEE Trans. Power Electron. 2018, 33, 6699-6709. [CrossRef]

63. Antonini, G. Spice equivalent circuits of frequency domain responses. IEEE Trans. Electromagn. Compat. 2003, 45, 502-512. [CrossRef]

64. Gustavsen, B.; Semlyen, A. Enforcing passivity for admittance matrices approximated by rational functions. IEEE Trans. Power Syst. 2001, 16, 97-104. [CrossRef]

65. Gustavsen, B. Wide band modeling of power transformers. IEEE Trans. Power Del. 2004, 9, 414-422. [CrossRef]

66. Sullivan, C.R.; Muetze, A. Simulation Model of Common-Mode Chokes for High-Power Applications. IEEE Trans. Ind. Appl. 2010, 46, 884-891. [CrossRef]

67. Nomura, K.; Kojima, T.; Hattori, Y. Straightforward Modeling of Complex Permeability for Common Mode Chokes. IEEJ J. IA 2018, 7, 462-472. [CrossRef] 
68. Cuellar, C.; Idir, N.; Benabou, A. High-Frequency Behavioral Ring Core Inductor Model. IEEE Trans. Power Electron. 2016, 31, 3763-3772. [CrossRef]

69. Illia, M.; Koleff, L.; Griepentrog, G. Non-ideal model of the common mode choke for EMI filters. In Proceedings of the 2017 IEEE Applied Power Electronics Conference and Exposition (APEC), Tampa, FL, USA, 26-30 March 2017; pp. 938-944.

70. Blanken, P.G.; Van Vlerken, J.J.L.M. Modeling of electromagnetic systems. IEEE Trans. Magn. 1991, 27, 4509-4515. [CrossRef]

71. Takahashi, S.; Ogasawara, S. A Novel Simulation Model for Common-Mode Inductors Based on Permeance-Capacitance Analogy. In Proceedings of the 2020 IEEE Energy Conversion Congress and Exposition (ECCE), Detroit, MI, USA, 11-15 October 2020; pp. 5862-5869.

72. Nomura, K.; Kikuchi, N.; Watanabe, Y.; Inoue, S.; Hattori, Y. Novel SPICE model for common mode choke including complex permeability. In Proceedings of the 2016 IEEE Applied Power Electronics Conference and Exposition (APEC), Long Beach, CA, USA, 20-24 March 2016; pp. 3146-3152.

73. Sixdenier, F.; Yade, O.; Martin, C.; Bréard, A.; Vollaire, C. How to include frequency dependent complex permeability into SPICE models to improve EMI filters design? AIP Adv. 2018, 8, 056604. [CrossRef]

74. Szabo, Z. Preisach functions leading to closed form permeability. Physica B 2006, 372, 61-67. [CrossRef]

75. Paul, C.R. Analysis of Multiconductor Transmission Lines; Wiley-IEEE Press: Hoboken, NJ, USA, 2007.

76. Achar, R.; Nakhla, M.S. Simulation of High-Speed Interconnects. Proc. IEEE 2001, 89, 693-728. [CrossRef]

77. Ametani, A. A General Formulation of Impedance and Admittance of Cables. IEEE Trans. Power Apparatus Syst. 1980, PAS-99, 902-910. [CrossRef]

78. Ametani, A.; Fuse, K. Approximate method for calculating the impedances of multiconductors with cross section of arbitrary shapes. Elect. Eng. Jpn. 1992, 112, 117-123. [CrossRef]

79. Dickinson, J.; Nicholson, P.J. Calculating the High Frequency Transmission Line Parameters of Power Cables. In Proceedings of the ISPLC, Minneapolis, MN, USA, 2-4 April 1997; pp. 127-133.

80. Idir, N.; Weens, Y.; Franchaud, J.-J. Skin Effect and Dielectric Loss Models of Power Cables. IEEE Trans. Dielect. Electr. Insul. 2009, 16, 147-154. [CrossRef]

81. Rivas, R.A.; Marti, J.R. Calculation of Frequency-Dependent Parameters of Power Cables: Matrix Partitioning Techniques. IEEE Trans. Power Deliv. 2002, 17, 1085-1092. [CrossRef]

82. Hoshmeh, A.; Schmidt, U. A Full Frequency-Dependent Cable Model for the Calculation of Fast Transients. Energies 2017, 10, 1158. [CrossRef]

83. Weens, Y.; Idir, N.; Bausiere, R.; Franchaud, J.J. Modeling and Simulation of Unshielded and Shielded Energy Cables in Frequency and Time Domains. IEEE Trans. Magn. 2006, 42, 1876-1882. [CrossRef]

84. Weens, Y.; Idir, N.; Franchaud, J.J.; Bausiére, R. HF Model of an Unshielded 2-Wire Energy Cable Submitted to Power Electronic Converter Constraints. Int. J. Model. Simul. 2008, 28, 292-298. [CrossRef]

85. Gustavsen, B.; Bruaset, A.; Bremnes, J.J.; Hassel, A. A Finite-Element Approach for Calculating Electrical Parameters of Umbilical Cables. IEEE Trans. Power Delivery 2009, 24, 2375-2384. [CrossRef]

86. Habib, S.; Kordi, B. Calculation of Multiconductor Underground Cables High-Frequency Per-Unit-Length Parameters Using Electromagnetic Modal Analysis. IEEE Trans. Power Deliv. 2013, 28, 276-284. [CrossRef]

87. Hafner, A.A.; Caballero, P.T.; Monteiro, J.H.A.; Costa, E.C.M.; Kurokawa, S.; Luz, M.V.F.; Carpes, W.P. Modeling of Power Cables with Arbitrary Cross Section: From Parameter Calculation to Electromagnetic Transients Simulation. J. Control Autom. Electr. Syst. 2017, 28, 405-417. [CrossRef]

88. Huangfu, Y.; Di Rienzo, L.; Wang, S. Frequency-Dependent Multi-Conductor Transmission Line Model for Shielded Power Cables Considering Geometrical Dissymmetry. IEEE Trans. Magn. 2018, 54, 1-4. [CrossRef]

89. Greedy, S.; Smartt, C.; Basford, M.J.; Thomas, D.W.P. Open Source Cable Models for EMI Simulations. IEEE Electromagn. Compat. Mag. 2018, 7, 69-81. [CrossRef]

90. Kruizinga, B.; Wouters, P.A.A.F.; Steennis, E.F. High Frequency Modeling of a Shielded Four-Core Low Voltage Underground Power Cable. IEEE Trans. Dielect. Electr. Insul. 2015, 22, 649-656. [CrossRef]

91. Patel, U.R.; Triverio, P. MoM-SO: A Complete Method for Computing the Impedance of Cable Systems Including Skin, Proximity, and Ground Return Effects. IEEE Trans. Power Deliv. 2015, 30, 2110-2118. [CrossRef]

92. Shafieipour, M.; Chen, Z.; Menshov, A.; De Silva, J.; Okhmatovski, V. Efficiently Computing the Electrical Parameters of Cables with Arbitrary Cross-Sections Using the Method-of-Moments. Electr. Power Syst. Res. 2018, 162, 37-49. [CrossRef]

93. Moreira, A.F.; Lipo, T.A.; Venkataramanan, G.; Bernet, S. High-Frequency Modeling for Cable and Induction Motor Overvoltage Studies in Long Cable Drives. IEEE Trans. Ind. Appl. 2002, 38, 1297-1306. [CrossRef]

94. Knockaert, J.; Peuteman, J.; Catrysse, J.; Belmans, R. A Vector Impedance Meter Method to Characterize Multiconductor Transmission-Line Parameters. IEEE Trans. Electromagn. Compat. 2010, 52, 1019-1025. [CrossRef]

95. Wang, L.; Ngai-Man Ho, C.; Canales, F.; Jatskevich, J. High-Frequency Modeling of the Long-Cable-Fed Induction Motor Drive System Using TLM Approach for Predicting Overvoltage Transients. IEEE Trans. Power Electron. 2010, 25, 2653-2664. [CrossRef]

96. Bade, T.G.; Roudet, J.; Guichon, J.-M.; Sartori, C.A.F.; Kuo-Peng, P.; Schanen, J.-L.; Derbey, A. Frequency-Domain Modeling of Unshielded Multiconductor Power Cables for Periodic Excitation with New Experimental Protocol for Wide Band Parameter Identification. Electr. Eng. 2019, 101, 333-343. [CrossRef] 
97. Williams, D.F. Multiconductor Transmission Line Characterization. IEEE Trans. Comp. Packag. Manuf. Technol. B 1997, 20, 129-132. [CrossRef]

98. Williams, D.F.; Rogers, J.E.; Holloway, C.L. Multiconductor Transmission-Line Characterization: Representations, Approximations, and Accuracy. IEEE Trans. Microw. Theory Tech. 1999, 47, 403-409. [CrossRef]

99. Wang, L.; Avolio, G.; Deconinck, G.; Lil, E.V.; Lai, L.L. Estimation of Multi-Conductor Powerline Cable Parameters for the Modelling of Transfer Characteristics. IET Sci. Meas. Technol. 2014, 8, 39-45. [CrossRef]

100. Gustavsen, B. Eliminating Measurement Cable Effects From Transformer Admittance Measurements. IEEE Trans. Power Deliv. 2016, 31, 1609-1617. [CrossRef]

101. Kim, J.-H.; Oh, D.; Kim, W. Accurate Characterization of Broadband Multiconductor Transmission Lines for High-Speed Digital Systems. IEEE Trans. Adv. Packag. 2010,33, 857-867. [CrossRef]

102. De Paula, H.; de Andrade, D.A.; Chaves, M.L.R.; Domingos, J.L.; de Freitas, M.A.A. Methodology for Cable Modeling and Simulation for High-Frequency Phenomena Studies in PWM Motor Drives. IEEE Trans. Power Electron. 2008, $23,744-752$. [CrossRef]

103. Marlier, C.; Videt, A.; Idir, N. NIF-Based Frequency-Domain Modeling Method of Three-Wire Shielded Energy Cables for EMC Simulation. IEEE Trans. Electromagn. Compat. 2015, 57, 145-155. [CrossRef]

104. Bogarra, S.; Riba, J.-R.; Sala-Caselles, V.; Garcia, A. Optimal Fitting of High-Frequency Cable Model Parameters by Applying Evolutionary Algorithms. Int. J. Electr. Power Energy Syst. 2017, 87, 16-26. [CrossRef]

105. Djordjevic, A.R. SPICE-Compatible Models for Multiconductor Transmission Lines in Laplace-Transform Domain. IEEE Trans. Microw. Theory Tech. 1997, 45, 569-579. [CrossRef]

106. Dounavis, A.; Achar, R.; Nakhla, M. A General Class of Passive Macromodels for Lossy Multiconductor Transmission Lines. IEEE Trans. Microw. Theory Tech. 2001, 49, 1686-1696. [CrossRef]

107. Tanji, Y.; Ushida, A. Closed-Form Expression of RLCG Transmission Line and Its Application. Electron. Comm. Jpn. Pt. III 2004, 87, 1-11. [CrossRef]

108. Gustavsen, B. Computer Code for Rational Approximation of Frequency Dependent Admittance Matrices. IEEE Trans. Power Deliv. 2002, 17, 1093-1098. [CrossRef]

109. Gustavsen, B. Computer Code for Passivity Enforcement of Rational Macromodels by Residue Perturbation. IEEE Trans. Adv. Packag. 2007, 30, 209-215. [CrossRef]

110. Gustavsen, B. Fast Passivity Enforcement for Pole-Residue Models by Perturbation of Residue Matrix Eigenvalues. IEEE Trans. Power Deliv. 2008, 23, 2278-2285. [CrossRef]

111. Krim, A.; Lakrim, A.; Tahri, D. Two VHDL-AMS-Based Models of Multi-Conductor Power Cables for EMI Simulations. Electr. Eng. 2020. [CrossRef]

112. Grivet-Talocia, S.; Huang, H.-M.; Ruehli, A.E.; Canavero, F.; Elfadel, I.M.A. Transient Analysis of Lossy Transmission Lines: An Efficient Approach Based on the Method of Characteristics. IEEE Trans. Adv. Packag. 2004, 27, 45-56. [CrossRef]

113. Dounavis, A.; Pothiwala, V.A. Passive Closed-Form Transmission Line Macromodel Using Method of Characteristics. IEEE Trans. Adv. Packag. 2008, 31, 190-202. [CrossRef]

114. Chinea, A.; Triverio, P.; Grivet-Talocia, S. Delay-Based Macromodeling of Long Interconnects from Frequency-Domain Terminal Responses. IEEE Trans. Adv. Packag. 2010, 33, 246-256. [CrossRef]

115. Grivet-Talocia, S.; Acquadro, S.; Bandinu, M.; Canavero, F.G.; Kelander, I.; Rouvala, M. A Parameterization Scheme for Lossy Transmission Line Macromodels With Application to High Speed Interconnects in Mobile Devices. IEEE Trans. Electromagn. Compat. 2007, 49, 18-24. [CrossRef]

116. Ferranti, F.; Antonini, G.; Dhaene, T.; Knockaert, L. Parametric Macromodeling of Lossy and Dispersive Multiconductor Transmission Lines. IEEE Trans. Adv. Packag. 2010, 33, 481-491. [CrossRef]

117. Morched, A.S.; Ottevangers, J.H.; Marti, L. Multi-Port Frequency Dependent Network Equivalents for the EMTP. IEEE Trans. Power Delivery 1993, 8, 1402-1412. [CrossRef]

118. Neumayer, R.; Haslinger, F.; Stelzer, A.; Weigel, R. Synthesis of SPICE-Compatible Broadband Electrical Models from n-Port Scattering Parameter Data. In Proceedings of the IEEE International Symposium on Electromagnetic Compatibility, Minneapolis, MN, USA, 19-23 August 2002; Volume 1, pp. 469-474.

119. Paul, C.R. Decoupling the Multiconductor Transmission Line Equations. IEEE Trans. Microwave Theory Tech. 1996, 44, 1429-1440. [CrossRef]

120. AbuShaaban, M.; Scanlan, S.O. Modal Circuit Decomposition of Lossy Multiconductor Transmission Lines. IEEE Trans. Microwave Theory Tech. 1996, 44, 1046-1056. [CrossRef]

121. Toulabi, M.S.; Wang, L.; Bieber, L.; Filizadeh, S.; Jatskevich, J. A Universal High-Frequency Induction Machine Model and Characterization Method for Arbitrary Stator Winding Connections. IEEE Trans. Energy Convers. 2019, 34, 1164-1177. [CrossRef]

122. Suresh, G.; Toliyat, H.A.; Rendusara, D.A.; Enjeti, P.N. Predicting the Transient Effects of PWM Voltage Waveform on the Stator Windings of Random Wound Induction Motors. IEEE Trans. Power Electron. 1999, 14, 23-30. [CrossRef]

123. Mohammed, O.A.; Ganu, S.; Abed, N.; Liu, S.; Liu, Z. High Frequency PM Synchronous Motor Model Determined by FE Analysis. IEEE Trans. Magn. 2006, 42, 1291-1294. [CrossRef]

124. Maki, K.; Funato, H.; Shao, L. Motor Modeling for EMC Simulation by 3-D Electromagnetic Field Analysis. In Proceedings of the 2009 IEEE International Electric Machines and Drives Conference, Miami, FL, USA, 3-6 May 2009; pp. $103-108$. 
125. De Gersem, H.; Muetze, A. Finite-Element Supported Transmission-Line Models for Calculating High-Frequency Effects in Machine Windings. IEEE Trans. Magn. 2012, 48, 787-790. [CrossRef]

126. Rahimi, A.; Kanzi, K. Improved High-Frequency Modeling of PMSM Using 3-D Finite Element Analysis. In Proceedings of the 2019 International Power System Conference (PSC), Tehran, Iran, 9-11 December 2019; pp. 71-78.

127. Zhong, E.; Lipo, T.A. Improvements in EMC Performance of Inverter-Fed Motor Drives. IEEE Trans. Ind. Appl. 1995, 31, 1247-1256. [CrossRef]

128. Weber, S.-P.; Hoene, E.; Guttowski, S.; John, W.; Reichl, H. Modeling Induction Machines for EMC-Analysis. In Proceedings of the 2004 IEEE 35th Annual Power Electronics Specialists Conference, Aachen, Germany, 20-25 June 2004; pp. 94-98.

129. Schinkel, M.; Weber, S.; Guttowski, S.; John, W.; Reichl, H. Efficient HF Modeling and Model Parameterization of Induction Machines for Time and Frequency Domain Simulations. In Proceedings of the Twenty-First Annual IEEE Applied Power Electronics Conference and Exposition, Dallas, TX, USA, 19-23 March 2006; pp. 1181-1186.

130. Mirafzal, B.; Skibinski, G.L.; Tallam, R.M.; Schlegel, D.W.; Lukaszewski, R.A. Universal Induction Motor Model with Low-to-High Frequency-Response Characteristics. IEEE Trans. Ind. Appl. 2007, 43, 1233-1246. [CrossRef]

131. Mirafzal, B.; Skibinski, G.L.; Tallam, R.M. Determination of Parameters in the Universal Induction Motor Model. IEEE Trans. Ind. Appl. 2009, 45, 142-151. [CrossRef]

132. Sun, J.; Xing, L. Parameterization of Three-Phase Electric Machine Models for EMI Simulation. IEEE Trans. Power Electron. 2014, 29, 36-41. [CrossRef]

133. Ryu, Y.; Park, B.-R.; Han, K.J. Estimation of High-Frequency Parameters of AC Machine from Transmission Line Model. IEEE Trans. Magn. 2015, 51, 1-4. [CrossRef]

134. Vidmar, G.; Miljavec, D. A Universal High-Frequency Three-Phase Electric-Motor Model Suitable for the Delta- and Star-Winding Connections. IEEE Trans. Power Electron. 2015, 30, 4365-4376. [CrossRef]

135. Sudhoff, S.D.; Tichenor, J.L.; Drewniak, J.L. Wide-Bandwidth Multi-Resolutional Analysis of a Surface-Mounted PM Synchronous Machine. IEEE Trans. Energy Convers. 1999, 14, 1011-1018. [CrossRef]

136. Idir, N.; Weens, Y.; Moreau, M.; Franchaud, J.J. High-Frequency Behavior Models of AC Motors. IEEE Trans. Magn. 2009, 45, 133-138. [CrossRef]

137. Jia, K.; Bohlin, G.; Enohnyaket, M.; Thottappillil, R. Modeling an AC Motor with High Accuracy in a Wide Frequency Range. IET Electr. Power Appl. 2013, 7, 116-122. [CrossRef]

138. Zhao, D.; Shen, K.; Liu, W.; Lang, L.; Liang, P. A Measurement-Based Wide-Frequency Model for Aircraft Wound-Rotor Synchronous Machine. IEEE Trans. Magn. 2019, 55, 1-8. [CrossRef]

139. Rahimi, A.; Kanzi, K. High-frequency modelling of permanent magnet synchronous motor for conducted EMI studies. IET Electr. Power Appl. 2020, 14, 2027-2036. [CrossRef]

140. Wang, S.; Lee, F.C.; Odendaal, W.G. Characterization and Parasitic Extraction of EMI Filters Using Scattering Parameters. IEEE Trans. Power Electron. 2005, 20, 502-510. [CrossRef]

141. Ansys Q3D Extractor, Version 2020 R2. Available online: https:/ /www.ansys.com/products/electronics/ansys-q3d-extractor (accessed on 21 January 2021).

142. CST Studio Suite. Available online: https://www.3ds.com/products-services/simulia/products/cst-studio-suite/ (accessed on 21 January 2021).

143. Dellis, J.-L. Zfit. Available online: https://www.mathworks.com/matlabcentral/fileexchange/19460-zfit (accessed on 21 January 2021).

144. Ma, C.L.; Lauritzen, P.O.; Sigg, J. Modeling of Power Diodes with the Lumped-Charge Modeling Technique. IEEE Trans. Power Electron. 1997, 12, 398-405. [CrossRef]

145. Palmer, P.R.; Santi, E.; Hudgins, J.L.; Kang, X.; Joyce, J.C.; Eng, P.Y. Circuit Simulator Models for the Diode and IGBT with Full Temperature Dependent Features. IEEE Trans. Power Electron. 2003, 18, 1220-1229. [CrossRef]

146. Bryant, A.T.; Kang, X.; Santi, E.; Palmer, P.R.; Hudgins, J.L. Two-Step Parameter Extraction Procedure with Formal Optimization for Physics-Based Circuit Simulator IGBT and p-i-n Diode Models. IEEE Trans. Power Electron. 2006, 21, 295-309. [CrossRef]

147. Prada, D.; Bellini, M.; Stevanovic, I.; Lemaitre, L.; Victory, J.; Vobecky, J.; Sacco, R.; Lauritzen, P.O. On the Performance of Multiobjective Evolutionary Algorithms in Automatic Parameter Extraction of Power Diodes. IEEE Trans. Power Electron. 2015, 30, 4986-4997. [CrossRef]

148. Budihardjo, I.; Lauritzen, P.G. The Lumped-Charge Power MOSFET Model, Including Parameter Extraction. IEEE Trans. Power Electron. 1995, 10, 379-387. [CrossRef]

149. McNutt, T.R.; Hefner, A.R.; Mantooth, H.A.; Berning, D.; Ryu, S.-H. Silicon Carbide Power MOSFET Model and Parameter Extraction Sequence. IEEE Trans. Power Electron. 2007, 22, 353-363. [CrossRef]

150. Gachovska, T.; Hudgings, J.L.; Bryant, A.; Santi, E.; Mantooth, H.A.; Agarwal, A.K. Modeling, Simulation, and Validation of a Power SiC BJT. IEEE Trans. Power Electron. 2012, 27, 4338-4346. [CrossRef]

151. SIMetrix/SIMPLIS SPICE Simulator Version 8.3. Available online: https:/ /www.simetrix.co.uk/ (accessed on 21 January 2021).

152. LTSpice SPICE Simulator. Available online: https://www.analog.com/en/design-center/design-tools-and-calculators/ltspicesimulator.html\# (accessed on 21 January 2021).

153. Sheng, K.; Williams, B.W.; Finney, S.J. A Review of IGBT Models. IEEE Trans. Power Electron. 2000, 15, 1250-1266. [CrossRef] 
154. Cavaiuolo, D. Compact Electro-Thermal Modeling of IGBT for Application Circuit Effective Design. Ph.D. Thesis, University of Naples Federico II, Naples, Italy, 2014.

155. Lauritzen, P.O.; Andersen, G.K.; Helsper, M. A Basic IGBT Model with Easy Parameter Extraction. In Proceedings of the IEEE Annual Power Electronics Specialists Conference, Vancouver, BC, Canada, 17 June 2001; pp. 2160-2165.

156. Chibante, R.; Araujo, A.; Carvalho, A. Finite-Element Modeling and Optimization-Based Parameter Extraction Algorithm for NPT-IGBTS. IEEE Trans. Power Electron. 2009, 24, 1147-1427. [CrossRef]

157. Chimento, F.; Mora, N.; Bellini, M.; Stevanovic, I.; Tomarchio, S. A Simplified Spice Based IGBT Model for Power Electronics Modules Evaluation. In Proceedings of the IECON 2011-37th Annual Conference of the IEEE Industrial Electronics Society, Melbourne, VIC, Australia, 7-10 November 2011; pp. 1155-1160.

158. Duan, Y.; Xiao, F.; Luo, Y.; Iannuzzo, F. A Lumped-Charge Approach Based Physical SPICE-Model for High Power Soft-Punch Through IGBT. IEEE J. Emerg. Sel. Top. Power Electron. 2019, 7, 62-70. [CrossRef]

159. Duan, Y.; Iannuzzo, F.; Blaabjerg, F. A New Lumped-Charge Modeling Method for Power Semiconductor Devices. IEEE Trans. Power Electron. 2020, 35, 3989-3996. [CrossRef]

160. Han, L.; Liang, L.; Kang, Y.; Qui, Y. A Review of SiC IGBT: Models, Fabrications, Characteristics, and Applications. IEEE Trans. Power Electron. 2021, 36, 2080-2093. [CrossRef]

161. Xu, Y.; Ngai-Man Ho, C.; Ghosh, A.; Muthumuni, D. An Electrical Transient Model of IGBT-Diode Switching Cell for Power Semiconductor Loss Estimation in Electromagnetic Transient Simulation. IEEE Trans. Power Electron. 2020, 35, $2979-2989$. [CrossRef]

162. Cao, H.; Ning, P.; Wen, X.; Yuan, T.; Li, H. An Electrothermal Model for IGBT Based on Finite Differential Method. IEEE J. Emerg. Sel. Topics Power Electron. 2020, 8, 673-684. [CrossRef]

163. Jing, L.; Du, M.; Wei, K.; Hurley, W.G. An Improved Behavior Model for IGBT Modules Driven by Datasheet and Measurement. IEEE Trans. Electron Devices 2020, 67, 230-236. [CrossRef]

164. Miyaoku, Y.; Tone, A.; Matsuura, K.; Miura-Mattausch, M.; Mattausch, H.J.; Ikoma, D. Compact Modeling of IGBT Charging/Discharging for Accurate Switching Prediction. IEEE J. Electron Devices Soc. 2020, 8, 1373-1380. [CrossRef]

165. Infineon IGBT Devices and Models. Available online: https://www.infineon.com/cms/en/product/power/igbt/igbt-discretes/ \#!simulation (accessed on 11 March 2021).

166. Kraus, R.; Turkes, P.; Sigg, J. Physics-based models of power semiconductor devices for the circuit simulator SPICE. In Proceedings of the 29th Annual IEEE Power Electronics Specialists Conference, Fukuoka, Japan, 22 May 1998; Volume 2, pp. 1726-1731. [CrossRef]

167. Shi, B.; Zhao, Z.; Zhu, Y. Piecewise Analytical Transient Model for Power Switching Device Commutation Unit. IEEE Trans. Power Electron. 2019, 34, 5720-5736. [CrossRef]

168. Krug, F.; Russer, P. The Time-Domain Electromagnetic Interference Measurement System. IEEE Trans. Electromagn. Compat. 2003, 45, 330-338. [CrossRef]

169. Heldwein, M.L.; Biela, J.; Ertl, H.; Nussbaumer, T.; Kolar, J.W. Novel Three-Phase CM/DM Conducted Emission Separator. IEEE Trans. Ind. Electron. 2009, 56, 3693-3703. [CrossRef]

170. Wang, S.; Lee, F.C.; Odendaal, W.G. Characterization, evaluation, and design of noise separator for conducted EMI noise diagnosis. IEEE Trans. Power Electron. 2005, 20, 974-982. [CrossRef]

171. Forsstrom, V.; Skibin, S.; Wunsch, B. Influence of Parasitic Coupling to Ground Plane on EMC Noise of Power Converters. In Proceedings of the International Symposium on Electromagnetic Compatibility-EMC EUROPE, Rome, Italy, 23-25 September 2020; pp. 1-5.

172. The Power Cables are the MCCMK 3x16/16 RM 1 kV and the MCMK 3x70/35 AN 1 kV Listed on Page 28 and 31 of the Catalogue. Available online: http:/ / media.drakakeila.ee/2016/01/Draka_Cataloque_EN.pdf (accessed on 11 March 2021). 